\title{
Experiments on the damage process in ice under compressive states of stress
}

\author{
B. M. Stone, ${ }^{1}$ I. J. Jordaan, ${ }^{1}$ J. Xiao, ${ }^{1}$ S. J. Jones ${ }^{2}$ \\ ${ }^{1}$ Ocean Engineering Research Centre, Faculty of Engineering and Applied Science, \\ Memorial University of Newfoundland, St. John's, Newefoundland, Canada \\ ${ }^{2}$ Institute for Marine Dynamics, National Research Council Canada, St. John's, Nerefoundland, Canada
}

\begin{abstract}
During ice-structure interaction, ice will fail in a brittle manner dominated by two processes. The first corresponds to the formation of macrocracks and the consequent spalling-off of large ice pieces. The second includes an intense shear-damage process in zones, termed critical zones, where high pressures are transmitted to the structure. The shear-damage process results in microstructural changes including microcrack formation and recrystallization. A range of tests on laboratory-prepared granular ice have been conducted to determine the fundamental behaviour of ice under various stress states and stress history, particularly as it relates to changes in microstructure. The test series was designed to study three aspects: the intrinsic creep properties of intact, undamaged ice; the enhancement of creep and changes in microstructure due to damage; and the effects of different stress paths. Tests on intact ice with triaxial confining pressures and low deviatoric stresses, aimed at defining the intrinsic creep response in the absence of microcracking, showed that an accelerated creep rate occurred at relatively low deviatoric stresses. Hence, a minimum creep rate occurred under these conditions. Recrystallization to a smaller grain-size and void formation were observed. Ice damaged uniaxially and triaxially prior to testing showed enhancement of creep under both uniaxial and triaxial loading conditions. Creep rates in triaxially damaged ice were found to be non-linear with high deviatoric stresses, corresponding to a power-law dependence of creep rate. Uniaxially damaged specimens contained microcracks parallel to the stressed direction which tended to close under triaxial confinement. Damage under triaxial conditions at low confining pressures produced small recrystallized grains near zones of microcracking. At high confining pressures, a fine-grained recrystallized structure with no apparent cracking was observed uniformly across the specimen. The recrystallization process contributes significantly to the enhanced creep rates found in damaged specimens.
\end{abstract}

\section{INTRODUCTION}

The design of structures and vessels for arctic and subarctic waters requires knowledge of ice loads and their distribution in space and time. In turn, this requires analysis of the interaction between the structure and the ice at the appropriate rate corresponding to the interaction being studied. These range from less than $1 \mathrm{~m} \mathrm{~d}^{-1}$ to several metres per second. Here we shall for the most part be concerned with the interaction at strain rates fast enough to cause brittle failure of ice. Field experiments show that this occurs at rates above about $1 \mathrm{mms}^{-1}$. The experiments concentrate on the zones where the ice is under predominantly compressive stresses, as typically occurs in ice-vessel interaction or the interaction of icebergs with fixed or floating structures.

Under these circumstances, the ice will fail in a brittle manner dominated by two processes. The first corresponds to the formation of macrocracks and consequent spalling-off of ice pieces. The second includes an intense shear-damage process in zones where high pressures are transmitted to the structure. This is a process where high shearing stresses, combined with hydrostatic pressure, lead to significant microstructural changes in the ice. The zones are termed critical zones (Jordaan and others, 1991). Figure 1 shows an idealization of a critical zone. At B the ice is well confined, whereas at $\mathrm{A}$ there is much less confinement. One of the

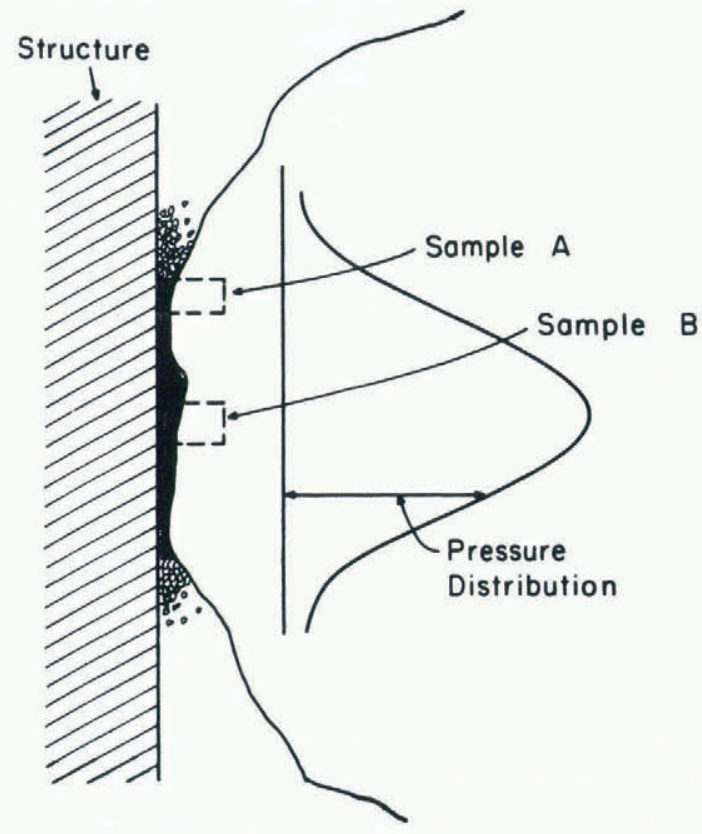

Fig. I. Schematic illustration of high-pressure contact zones, termed critical zones. 
objects of this work was to study the effect of such confinement in triaxial compressive tests. In field experiments, pressures up to $70 \mathrm{MPa}$ have been observed on small sensors $13 \mathrm{~mm}$ in diameter (Frederking and others, 1990). Iceindentation experiments in the field have also shown that forms of microstructural change other than microcracking occur, resulting in a fine-grained distinct layer of ice adjacent to the structure. This layer of crushed ice was about 25-65 $\mathrm{mm}$ in mean thickness for indenters up to $3 \mathrm{~m}^{2}$ in area (Kennedy and others, 1994). Reference should also be made to the pioneering work of Kheisin and Cherepanov (1973). There is considerable dynamic activity during the interaction process (Jordaan and Timco, 1988; Frederking and others, 1990). During this process the microstructurally modified, crushed ice is extruded from the layer adjacent to the structure. The rapid drop in load in these tests is associated with this crushing and extrusion process. The processes that result in changes to the microstructure and in the sudden reduction in load with associated deformation and temperature variation include (1) microfracturing, (2) pressure melting, and (3) dynamic recrystallization.

Recrystallization has often been observed in the slow flow of ice, e.g. glaciers (Hobbs, 1974). This process was also studied in tests on friction (Barnes and others, 1971; Offenbacher and others, 1973), in which recrystallization occurred under loading rates greater than observed in slow flow, and resulted in enhanced creep rates, with a $c$-axis orientation favourable to creep in the basal plane. Duval and others (1983) provide an explanation of tertiary creep based on the recrystallization process. According to these authors, the onset of dynamic recrystallization occurs at a critical difference in the free energy of adjacent grains, and moves as a wave through the material. Frederking and Gold (1975) observed recrystallization in indentation experiments, in areas of relatively high shear stress.

The present research group introduced an innovative experimental procedure, in which the ice specimen is subjected to prescribed histories of stress and strain, thus causing microstructural change before the test. Damage is defined as change to the microstructure caused by previous history of stress and strain. It is characterized by recrystallization and the presence of microcracks. In order to take into account the changing microstructure (microcrack formation and recrystallization), state variables to represent the prior stress-strain history have been introduced. These are typically of the following form (Schapery, 1981, 1991; Jordaan and Xiao, 1993; Xiao and Jordaan, 1996):

$$
S=\int_{0}^{t}\left(\frac{\sigma}{\sigma_{1}}\right)^{q} \mathrm{~d} \tau
$$

where $\sigma$ is stress, $\sigma_{1}$ is nominal reference stress and $q$ is a constant $(\approx 5)$. The state variable $S$ therefore takes into account stress history. Shear stresses are the predominant cause of damage, but concurrent hydrostatic pressure must also be taken into account. Previous experimental work by the present research group on ice that has undergone changes to its microstructure (Stone and others, 1989; Jordaan and others, 1992) was focussed on the effects of microcracking on the stress-strain response of ice. The main effect of microstructural change was a reduction in elastic modulus and a large enhancement in the creep rate. In addition to microcracking, as noted, other mechanisms such as pressure melting and recrystallization could have been present, especially under triaxially confined states of stress.
Clarification of the processes and their effects is important to the understanding of the mechanics of ice-structure interaction. Also, in the characterization of damage, assumptions have been made which require validation or correction. Therefore, an experimental programme was conducted. This programme also served to clarify the following issues:

(1) The intrinsic creep response of ice in the intact, undamaged state is required for analysis of creep response in the damaged state (Xiao and Jordaan, 1996). Tests have been conducted to study this aspect, in particular the question of the minimum creep rate.

(2) The kinds of microstructural change are important for the sound application of damage mechanics. The changes include microcracking and recrystallization which result from stress and strain history. Evidence from thin sections is the principal method.

(3) The stress - strain relationship, as a function of previous stress-strain history, is essential to analysis of the critical zones, as is the effect of stress path on the response of ice, particularly under the unloading conditions described above.

\section{EXPERIMENTAL PROGRAMME}

\subsection{Notation}

The convention adopted here is that which is most used in the geophysical sciences, whereby $\sigma_{1} \geq \sigma_{2} \geq \sigma_{3}$ and compressive stresses are assumed positive. The stress and strain can be expressed in terms of the volumetric and deviatoric components. In the tests under triaxial conditions to be described, the specimen was subjected to hydrostatic pressure and an axial stress (Fig. 2). The value $\left(\sigma_{1}-\sigma_{3}\right)$ is denoted the stress difference, and it can be shown that this is equal to the von Mises stress $s$, given by

$$
s^{2}=\frac{3}{2}\left(s_{1}^{2}+s_{2}{ }^{2}+s_{3}{ }^{2}\right)
$$

where $s_{1}, s_{2}$ and $s_{3}$ are the deviatoric stresses corresponding to directions 1,2 and 3.

The tests on stress path are demonstrated in Figure 3. The path $\mathrm{OA}$ is along the hydrostatic axis $\left(\sigma_{1}=\sigma_{2}=\sigma_{3}\right)$. The path AB illustrates the conventional triaxial test, corre-

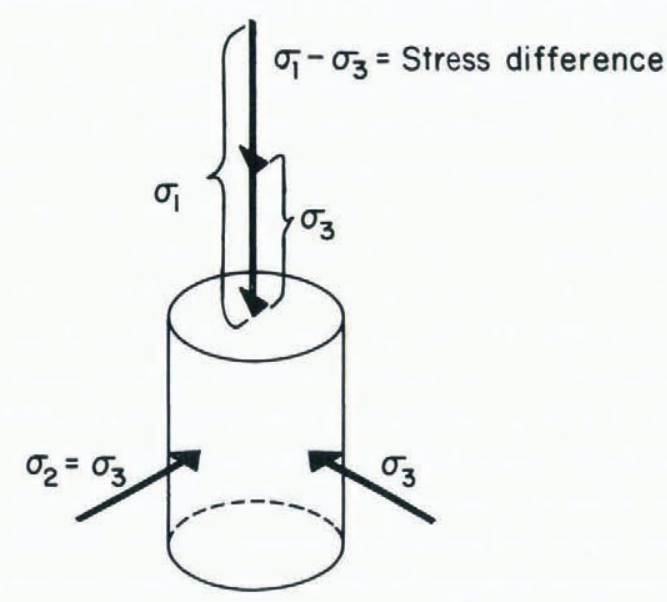

Fig. 2. Triaxial test, specimen subjected to hydrostatic pressure and an axial stress. 


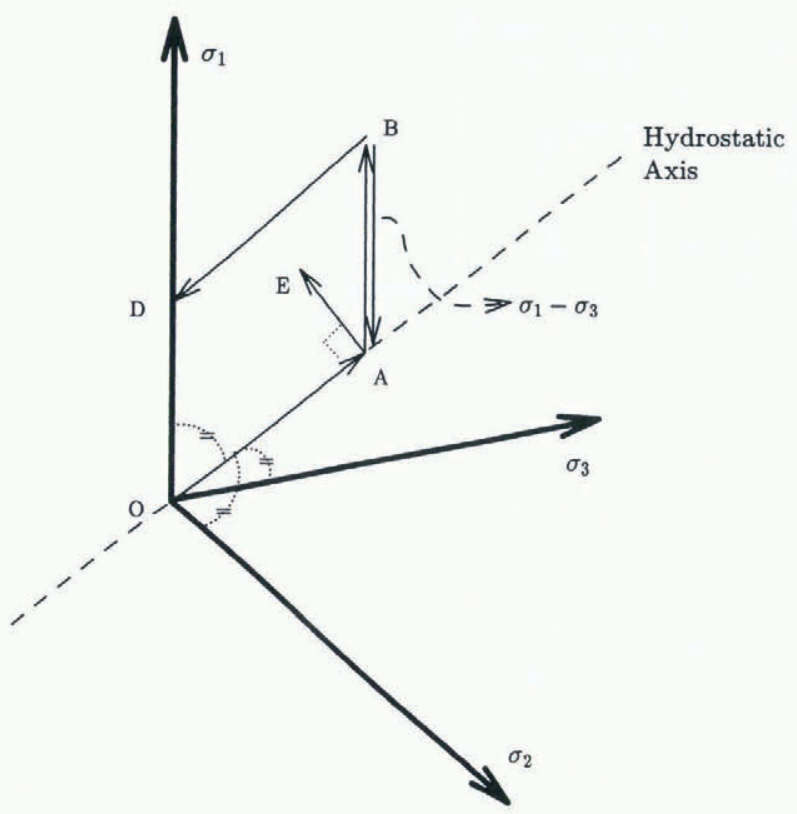

Fig. 3. Stress paths in principal stress space.

sponding to the increase of axial stress $\sigma_{1}$ on a cylindrical specimen. Stress in the deviatoric plane (AE) can be applied (see Singh, 1993). The path BD illustrates a possible path for removal of hydrostatic pressure while maintaining axial pressure. This path was used in three tests (see section $3.3)$.

\subsection{Test specimens}

All tests were conducted using laboratory-prepared granular ice following the procedure detailed by Stone and others (1989). To minimize the final air content of the ice while maintaining control over grain-size, the following equipment and procedure were used (Fig. 4). Bubble-free columnar grained ice produced from distilled, deionized and deaerated water frozen unidirectionally was crushed and sieved to produce $2.00-3.36 \mathrm{~mm}$ seeds. A cylindrical, acrylic mould, $229 \mathrm{~mm}$ in diameter, $303 \mathrm{~mm}$ in length, was filled with this seed. The bottom of the mould, constructed of aluminium, was sealed with $\mathrm{O}$-rings and equipped with an airtight valve. The top of the mould consisted of a flexible latex membrane sealed against the wall of the mould using elastic bands and silicone grease. The filled mould was attached, via rubber tubing and a three-way valve, to both a vacuum pump and deaerator.

The mould, with seed ice and connecting tubing, was

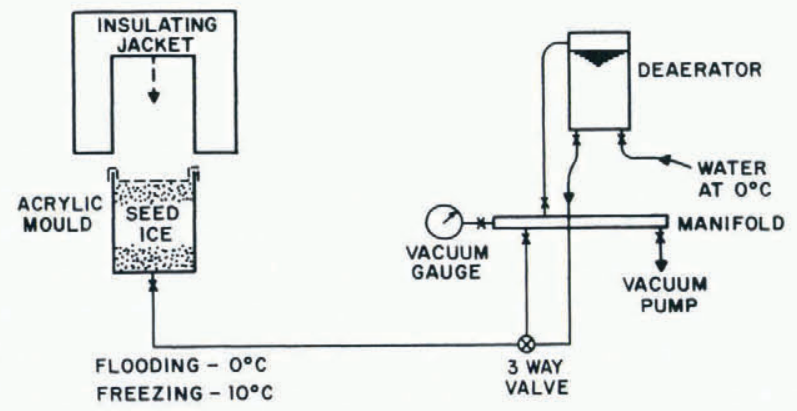

Fig. 4. Equipment and procedure, laboratory-prepared granularice. placed under a vacuum of 270-400 $\mathrm{Pa}(2.0-3.0$ torr) for a period of $1.5-2 \mathrm{~h}$. After evacuation, distilled and deionized water cooled to $0^{\circ} \mathrm{C}$ was transferred to the deaerator and deaerated for $15 \mathrm{~min}$. The mould was then completely flooded with this deaerated water via the evacuated tubing and three-way valve without any further contact with the atmosphere.

After flooding, the airtight valve was closed and the mould disconnected. The mould, supported above floor level, was then covered with an insulating jacket leaving the bottom exposed. Freezing was primarily unidirectional from the exposed bottom up, and was completed in approximately $3 \mathrm{~d}$, at a cold-room temperature of $-10^{\circ} \mathrm{C}$. The ice was removed from the mould by allowing it to warm slightly and slide from the mould.

Typically, the freezing procedure produced larger than desired grains near the bottom and outside perimeter, and a higher density of bubbles near the top. To ensure consistent repeatable ice quality, the top and bottom $30 \mathrm{~mm}$ were removed and discarded. Four cylindrical samples were then cut from the large cylinder such that the outside perimeter was also discarded.

The rough-cut specimens were machined to the desired diameter using a lathe. Subsequently, the desired length, with ends parallel and perpendicular to the centre axis, was obtained using a special double fly cutter in a horizontal milling machine with the specimen held in a precision vice. Both ends were machined simultaneously. The final test specimens used measured $70 \pm 0.05 \mathrm{~mm}$ diameter by $175 \pm 1.0 \mathrm{~mm}$ length.

The crystal structure of each batch of four specimens was checked by taking a thin section at the immediate top and bottom of random specimens throughout a given batch. Mean grain diameter based on the number of grains per unit area and assuming spherical grains of constant size (Cole, 1986) was $3.5 \mathrm{~mm}$. The $c$-axis orientation was determined using a universal stage with azimuths and inclinations plotted on a Lambert equal-area projection. Random $c$-axis orientation was evident in each case.

The ice produced by the above procedure is largely transparent through the $70 \mathrm{~mm}$ diameter with minimal bubble content. Stone and others (1989) demonstrated that density measurements did not provide an adequate quantitative measure of the low bubble content achieved by the ice-production process used. The values were, in fact, equal to $0.917 \pm 0.0005 \mathrm{~g} \mathrm{~cm}^{-3}$ at -4 C.

\subsection{Test equipment and procedure}

An MTS Systems Corp. Teststar Material Test System integrated with a Structural Behaviour Engineering Laboratories (SBEL) Model 10 triaxial cell was used for all tests (Fig. 5). The dual-axis digital control system permitted full, uninterrupted closed-loop feedback cont rol of both the axial load frame and the triaxial cell confining pressure across the full range of control modes. The four-column axial load frame and actuator have a dynamic capacity of $500 \mathrm{kN}$. Both the MTS Confining Pressure Intensifier and the triaxial cell have a capacity of $69 \mathrm{MPa}$. In all cases, the complete test sequence, including machine operation, test execution, control-mode changes and data acquisition, was pre-programmed using MTS Testware SX software.

The triaxial cell with overall internal dimensions of $241 \mathrm{~mm}$ diameter by $356 \mathrm{~mm}$ height supports a specimen 


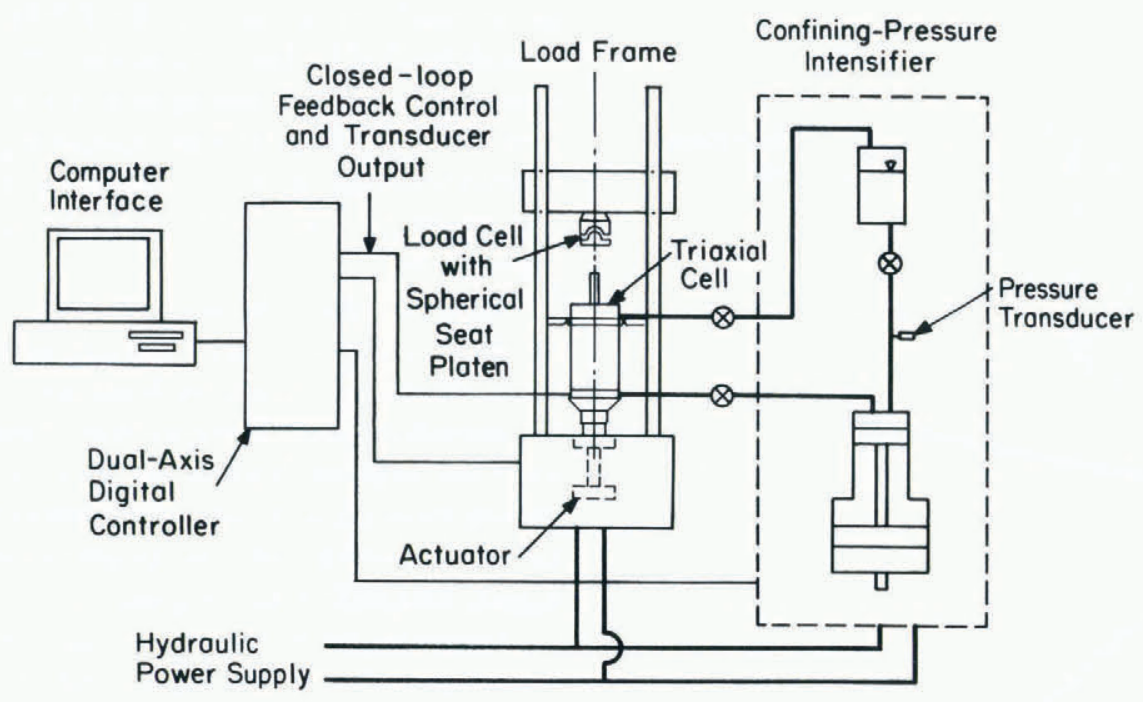

Fig. 5. Test apparatus: MTS dual-axis Teststar system with SBEL triaxial cell.

size of up to $102 \mathrm{~mm}$ in diameter, confining pressures to $69 \mathrm{MPa}(10000 \mathrm{psi})$, and axial loads to $1300 \mathrm{kN}(300000$ lb). Dow Corning silicone 200 fluid with a viscosity of $10^{-5} \mathrm{~m}^{2} \mathrm{~s}^{-1}(10 \mathrm{cSt})$ was used as the confining fluid. This non-conducting transparent fluid has a relatively flat viscosity-temperature curve, permitting easy serviceability at temperatures down to $-40^{\circ} \mathrm{C}$. Four-pin hermetically sealed electrical feed-throughs permit easy access to in-vessel instrumentation. The transfer of confining fluid to and from the cell was done using the valve-control system and pump of the confining-pressure intensifier.

Data recorded included time, stress difference, axial strain, lateral strain and triaxial confining pressure. The acquisition rates were varied depending on the test process and its duration, so as to keep data files to a reasonable size, for example, from 2.5 samples per second during the damage step to 25 per second during pulse loading. The Teststar data acquisition provides 16 -bit resolution across 16 channels, with simultaneous sample and hold providing sampling across all channels at the same time.

The stress difference applied was measured using the load cell of the axial load frame external to the triaxial cell. The total force measured included a component attributable to the counteracting force of the hydrostatic confining pressure. This force due to the hydrostatic pressure was measured, and subtracted from the measured total force to give the force difference.

Axial strain was measured using two in situ linear variable differential transformers mounted directly on the sample $180^{\circ}$ apart over an initial gauge length of approximately $120 \mathrm{~mm}$ using specially designed collars. The two linear variable differential transformers outputs were averaged to provide both an in situ measurement of strain and a closedloop feedback-control signal when needed.

Lateral strains were measured using specially designed double cantilever beams with a full-bridge strain gauge array. Three transducers were mounted across the diameter of the sample at approximately the top, centre and bottom of the gauge length. The gauge length of these transducers could be varied to apply a gentle pressure to the sample for mounting, and they were further secured by elastic bands. The change in diameter at the three locations as measured by the transducer was measured and recorded separately. After testing, an average value was used to obtain radial strain. The volumetric strain was then obtained using axial strain and radial strain.

The temperature during each test was measured using fast-response resistance temperature detector elements immersed in the confining fluid and implanted in the centre of a specimen within the triaxial cell. All tests were conducted at an initial confining-fluid and specimen temperature of $-10 \pm 0.5^{\circ} \mathrm{C}$. The results indicate that under the highest pressure of $20 \mathrm{MPa}$, the temperature of the specimen increased by $0.3^{\circ} \mathrm{C}$ immediately upon application of the confining pressure. A further increase of $0.8^{\circ} \mathrm{C}$ could occur during the test as a result of heat transfer from the confining fluid.

\section{TEST PROGRAMME AND RESULTS}

The test series was designed to study three aspects: the intrinsic creep properties of intact (i.e. undamaged) ice; the enhancement of creep and changes in microstructure due to damage; and effects of different stress paths.

\subsection{Intrinsic creep properties}

\subsubsection{Rationale and programme}

The creep properties of intact (i.e. undamaged) granular ice were measured by applying a small stress difference, up to $2.3 \mathrm{MPa}$, over a long time duration, up to $12 \mathrm{~h}$. A hydrostatic pressure was applied in order to suppress the initiation of cracks, and then the creep response that resulted from a small stress difference was measured for a period of time. It should be noted that the existence of a minimum creep rate has been questioned (Schapery, 1991). At low stresses and strain rates, Jacka (1984) has shown, a minimum strain rate occurs in the creep of ice at a total octahedral strain of about $0.6 \%$. At higher strain rates, Sinha $(1989,1990)$ has suggested, microcracking and accumulated damage during primary creep may be so important that a minimum creep rate is of limited value. One of the aims of this work was to study ice under relatively high strain rates but under confined conditions where cracking would be suppressed. 
In accordance with this objective, three tests have been conducted on intact specimens under $20 \mathrm{MPa}$ triaxial confinement:

Test l: $1.8 \mathrm{MPa}$ stress difference applied for $12 \mathrm{~h}$ followed by $12 \mathrm{~h}$ relaxation.

Test 2: $2.0 \mathrm{MPa}$ stress difference applied for $12 \mathrm{~h}$ followed by $12 \mathrm{~h}$ relaxation.

Test 3: $2.3 \mathrm{MPa}$ stress difference applied for $8 \mathrm{~h}$ followed by $8 \mathrm{~h}$ relaxation. The initial load and relaxation sequence was immediately followed by a repeat sequence.

\subsubsection{Results and discussion}

The creep response of these tests is shown in Figure 6. For test 3 the creep following first loading only is shown. Figure 7 shows the creep response of the initial and repeat test sequence of test 3 .

Using the conventional division of creep into three phases - primary, secondary and tertiary - the $1.8 \mathrm{MPa}$ stress applied in test 1 clearly demonstrates the primary and secondary phases of creep in ice. The transition to tertiary does occur at about $7 \mathrm{~h}$ in test 2, where the applied stress difference was increased to $2.0 \mathrm{MPa}$. The 2.3 $\mathrm{MPa}$

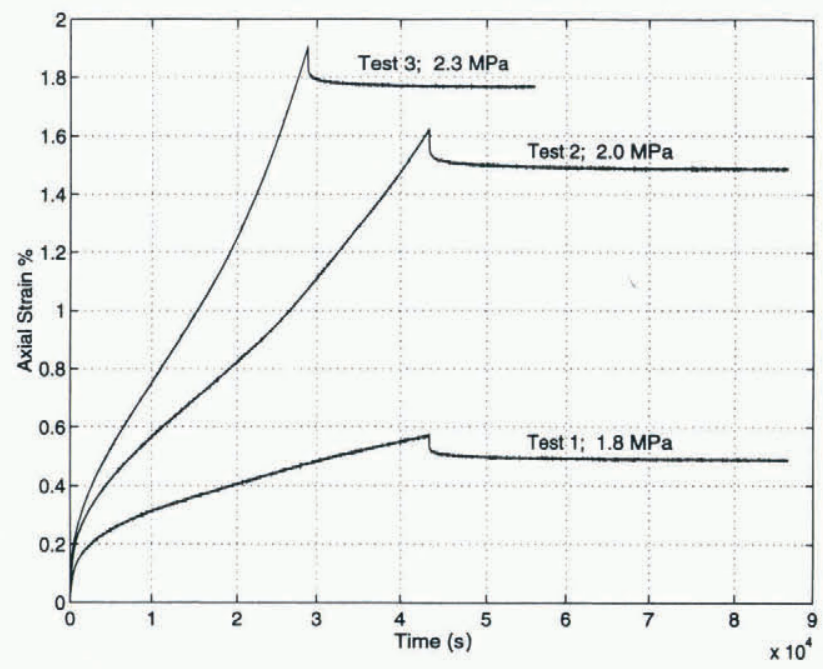

Fig. 6. Creep response of intact ice under 20 MPa triaxial confinement and stress differences of 1.8, 2.0 and 2.3 MPa.

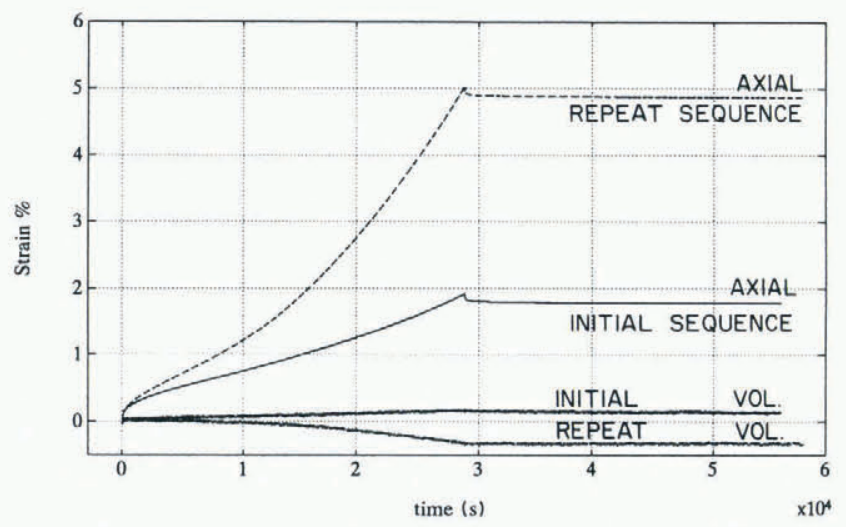

Fig. 7. Axial and volumetric strain of initial and repeat $8 \mathrm{~h}$ $2.3 \mathrm{MPa}$ pulse-load and $8 \mathrm{~h}$ relaxation sequence under 20 MPa triaxial confinement (lest 3). stress difference of test 3 reduces the time to minimum creep rate to about $4 \mathrm{~h}$. The repeat load sequence of test 3 indicates that the specimen had undergone significant change, since the strain response was quite different when compared to the initial load sequence. Maximum total strain at the end of the second $8 \mathrm{~h}$ load pulse is $5 \%, 2.5$ times that of the initial test, with tertiary creep occurring earlier at about $2.7 \mathrm{~h}$.

Typical cross-polarized thin sections of the ice prior to and after testing are shown in Figures 8 and 9. In all cases, there was a breakdown of grain structure and associated recrystallization. The change in grain-size was more marked for higher stress differences. It should be noted that the after-test thin section of test 3 (Fig. 9c) was taken after completion of the repeat load sequence and a total strain of $7 \%$. In this case, the change in structure is uniform across the specimen, with a reduction in mean grain diameter from 3.5 to $2.3 \mathrm{~mm}$. A number of small voids between crystals was also observed in the after-test thin section during microtoming.

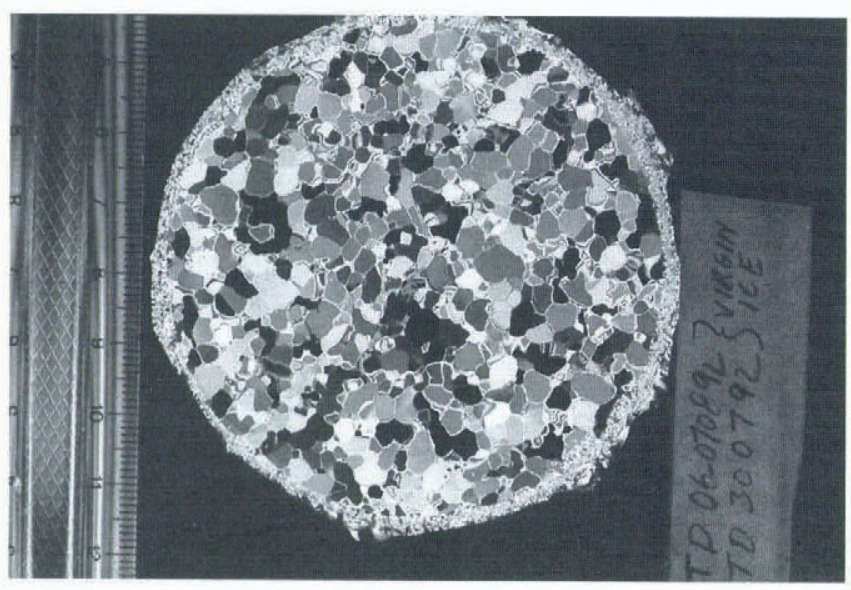

Fig. 8. Typical thin section of ice prior to testing.

Although the confining pressure suppressed microcracks as observed in thin sections after the test compared to uniaxially loaded specimens, the microstructure did not remain unaltered, and two modifications, recrystallization and void formation, were observed. The acceleration of creep is likely to be associated with these microstructural changes. It is likely that the greatly enhanced strains observed in the repeat load sequence of test 3 are associated with void formation since the increased strain rate occurred concurrently with the volume increase (Fig. 7).

Compression tests with a number of sequential pulse loads of short duration (20 and $100 \mathrm{~s}$ ) were also conducted on intact ice. These were essentially companion tests for comparison with those on damaged ice and will therefore be presented in section 3.2 .

\subsection{Damaged ice and creep enhancement}

\subsubsection{Rationale and programme}

Compression tests were conducted on both intact and damaged specimens under uniaxial conditions and triaxial confining pressures $(5,10$ and $20 \mathrm{MPa})$. The stress-strain and strain-time curves were used to quantify the creep response as a function of damage and triaxial confinement pressure. Any microstructural changes occurring were de- 


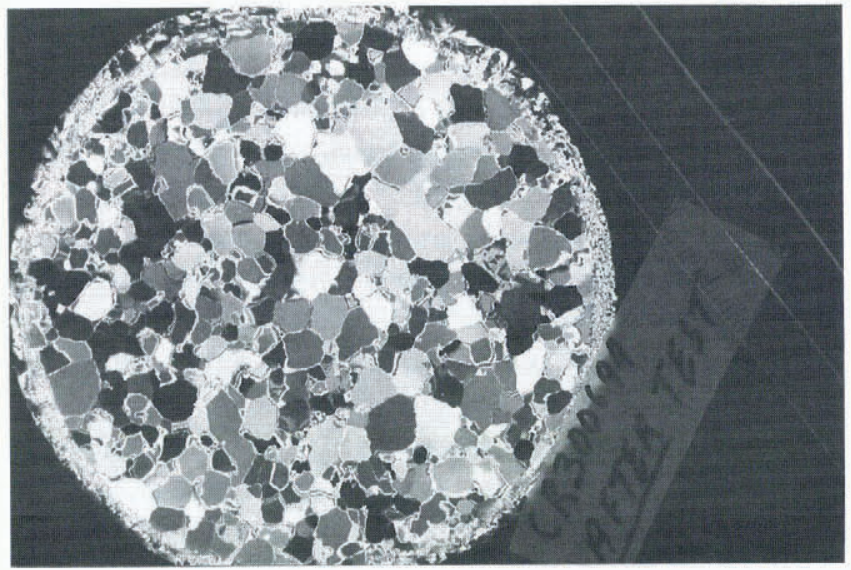

a

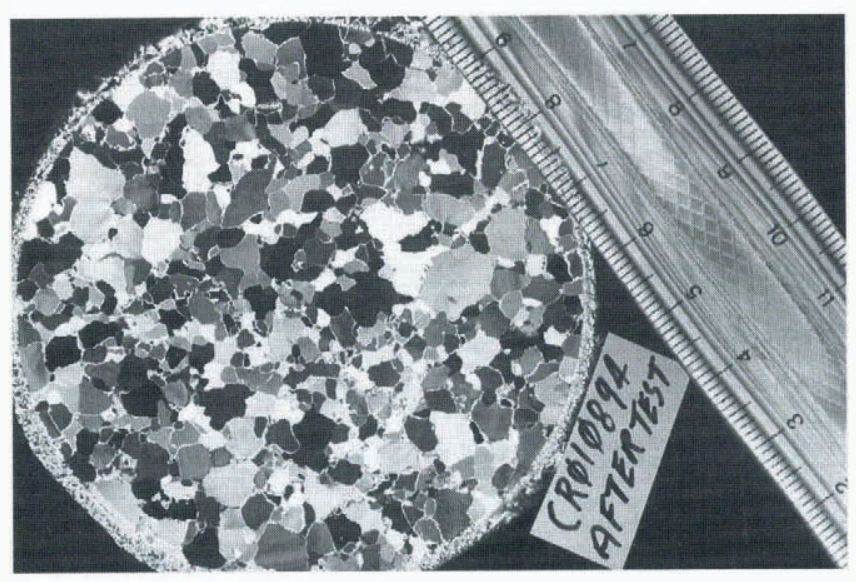

b

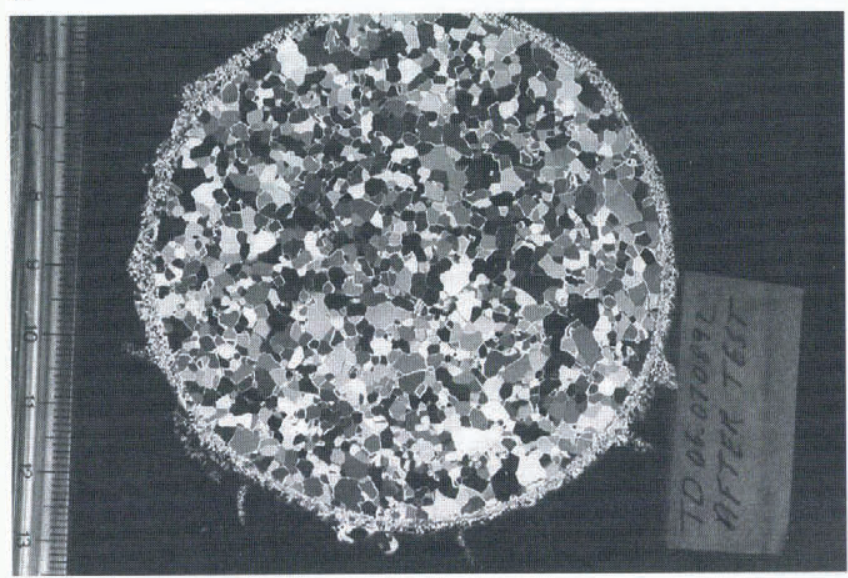

c

Fig. 9. Thin sections after testing: (a) test 1, 1.8 MPa stress difference; (b) test 2, 2.0 MPa stress difference; and (c) test 3, 2.3 MPa stress difference.

fined through thin sections taken before and after the test. A variety of damage levels was created by compressing otherwise undamaged, intact samples at a strain rate of $10^{-4} \mathrm{~s}^{-1}$ to a total axial strain of $2 \%$ or $4 \%$. These damage steps were applied either uniaxially or under the triaxial confinement pressure $(5,10$ and $20 \mathrm{MPa})$ to be applied in the particular test. Typical stress-strain curves for each of the $2 \%$ and $4 \%$ total strain damage steps are shown in Figure 10. The damage-level notation is $X \% \mathrm{U}, X \% 5, X \% 10$ and $X \% 20$ where $X$ is percentage strain achieved at a rate of $10^{-4} \mathrm{~s}^{-1}$ uniaxially $(\mathrm{U})$ or under triaxial confining pressure $(5,10$ or $20 \mathrm{MPa}$ ). Following the damage step, the specimen was unloaded. It was then subjected to a test sequence involving the application of a number of 1,2 and $3 \mathrm{MPa}$ stress differences (instant load and unload) each for a period of $20 \mathrm{~s}$ followed by either a 200 or 400 s relaxation period. In most cases, the initial stress sequence above was common to all tests, and was followed by a sequence of higher pulse loads, up to $10 \mathrm{MPa}$, for a longer duration $(100 \mathrm{~s})$. These were, in turn, followed by a longer relaxation period (800s). The small stress pulses were designed to avoid further damage, while giving the strain compliance. The higher pulses gave information on non-linearities with stress, but further damage was likely to occur concurrently with the stress.

\subsubsection{Results and discussion}

In earlier tests, Jordaan and others (1992) examined the creep response of intact (i.e. undamaged) and damaged ice (to $2 \%$ total strain at $10^{-4} \mathrm{~s}^{-1}$ ) under uniaxial conditions. The results are shown in Figure 11. Comparison of the creep response of intact and $2 \%$ uniaxially damaged ice shows that elastic strain has not increased significantly as a result of the damage; delayed elastic strain was increased by several orders of magnitude. The stress pulses used for these tests $(0.25,0.5$ and $0.75 \mathrm{MPa})$ resulted in negligible additional damage after repeated loadings.

Figures $12-14$ show the creep response of intact ice, as well as $2 \%$ and $4 \%$ uniaxially damaged ice, all tested subsequently to the damage step under triaxial confining pressures of 5,10 and $20 \mathrm{MPa}$. The damage state has virtually no effect on the elastic-strain component under each of the three confining pressures. At a confining pressure of $5 \mathrm{MPa}$ there is virtually no difference in the creep response of intact and $2 \%$ uniaxially damaged ice for any of the three pulse loads (Fig. 12). For intact ice and damage states, $2 \% \mathrm{U}$ and $4 \% \mathrm{U}$, tested at 10 and $20 \mathrm{MPa}$ confining pressure, the strain-compliance enhancement associated with damage is clearly evident for the $3 \mathrm{MPa}$ pulse, and less so for smaller ( 1 and $2 \mathrm{MPa}$ ) pulses. Unlike the large increases shown in the previous uniaxial tests (Fig. 11), relatively small increases in delayed elastic creep as a function of uniaxial damage state were observed under triaxial confinement.

Figures 15-17 show the creep response of $2 \%$ and $4 \%$ triaxially damaged ice along with that of the intact ice previously shown in Figures 12-14. In these tests, the 2\% and $4 \%$ total strain at $10^{-4} \mathrm{~s}^{-1}$ damage step was executed under the same triaxial confining pressure as the pulse loads of the particular test. As previously, there is virtually no effect on elastic strain. However, the delayed elastic or primary creep strain, is larger for those samples damaged under triaxial conditions than for those damaged under uniaxial conditions, although there is little difference between those damaged under 5, 10 and $20 \mathrm{MPa}$. In other words, there is little difference between the $4 \% 5,4 \% 10$ and $4 \% 20$ curves in Figures 15, 16 and 17a when they are compared at the same pulse load, but all are significantly different from the $4 \% \mathrm{U}$ curve of Figure 14. Figure 17b shows the effect of larger load pulses, up to $7 \mathrm{MPa}$, for a longer duration, $100 \mathrm{~s}$. Clearly the strain developed is greater, as expected for a larger applied stress, because, for ice, strain rate is proportional to stress to a power of about 3 . A reduced grain-size was noted in the thin section shown in Figure 9c, taken at the end of an extended creep test on an intact specimen under $20 \mathrm{MPa}$ confining and $2.3 \mathrm{MPa}$ additional stress difference. Figure 18 shows the thin section of a specimen after $2 \%$ uniaxial damage and a 1,2,3,1 $\mathrm{MPa}, 20 \mathrm{~s}$, pulse-load sequence under 


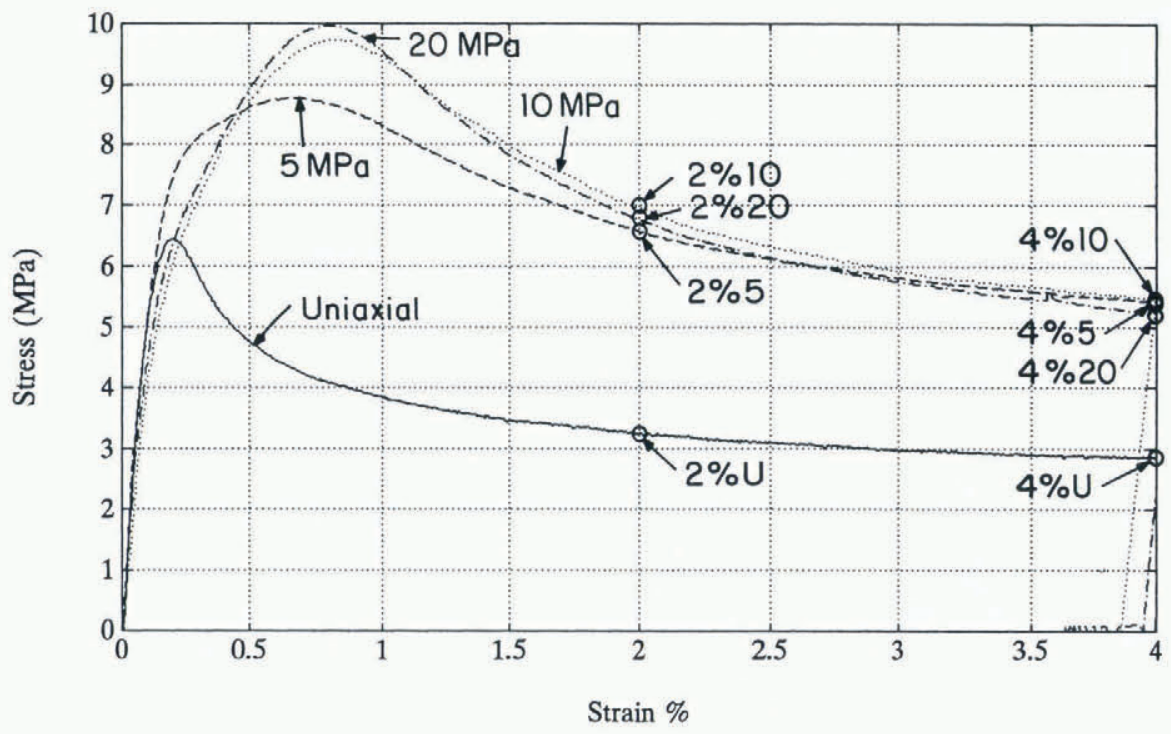

Fig. 10. Damage states created by compressing undamaged intact samples at a strain rate of $10^{-4} \mathrm{~s}^{-1}$ to a total strain of $2 \%$ or $4 \%$.

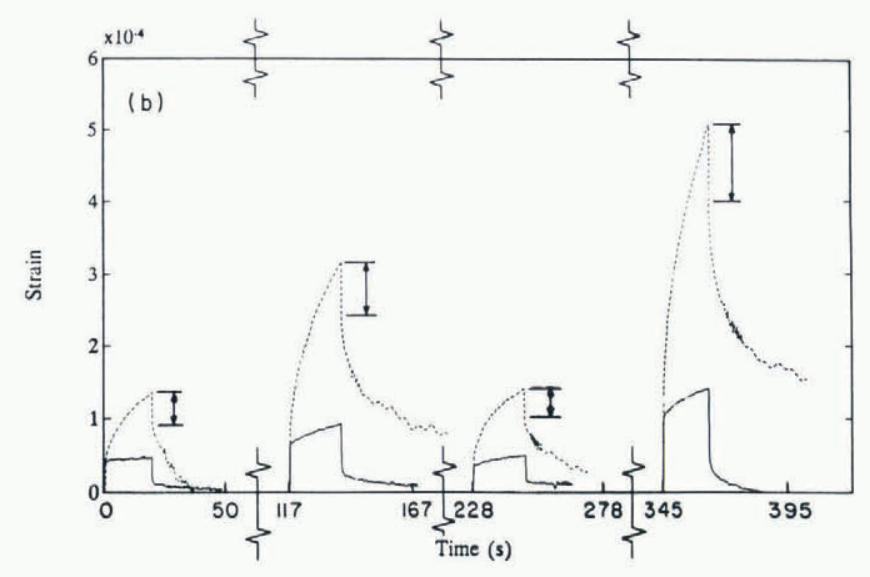

Fig. 11. Creep response of intact (solid line) and $2 \%$ uniaxially damaged ice (dashed line) for 20 spulse-load sequence of 0.25/0.5/0.25/0.75 MPa under uniaxial conditions (Jordaan and others, 1992). triaxial confinement of $10 \mathrm{MPa}$. Cracks along and across grain boundaries, with fine particles dispersed throughout the section, are readily apparent on the magnified section (Fig. 18b).

A significant difference between the damage states under uniaxial and triaxial stress states is the introduction of microcracks. Under uniaxial conditions, the damage introduced by a $4 \%$ strain consists mainly of microcracks parallel to the axis of loading. These microcracks will tend to introduce anisotropy. Under triaxial conditions, these microcracks will be suppressed (see Fig. 19), and the damage introduced will be mostly dislocation generation and plastic deformation. Figure 20 shows two strain-history curves for creep tests under $10 \mathrm{MPa}$ triaxial confinement on damaged samples I $(4 \% 10)$ and II $(4 \% \mathrm{U})$. The strain history from 0 to A corresponds to the formation of the damage. The period $\mathrm{A}-\mathrm{B}$ corresponds to the sequence of creep tests. In the case of uniaxial damage $(4 \% \mathrm{U})$, microcracks were developed along the direction of loading stress,

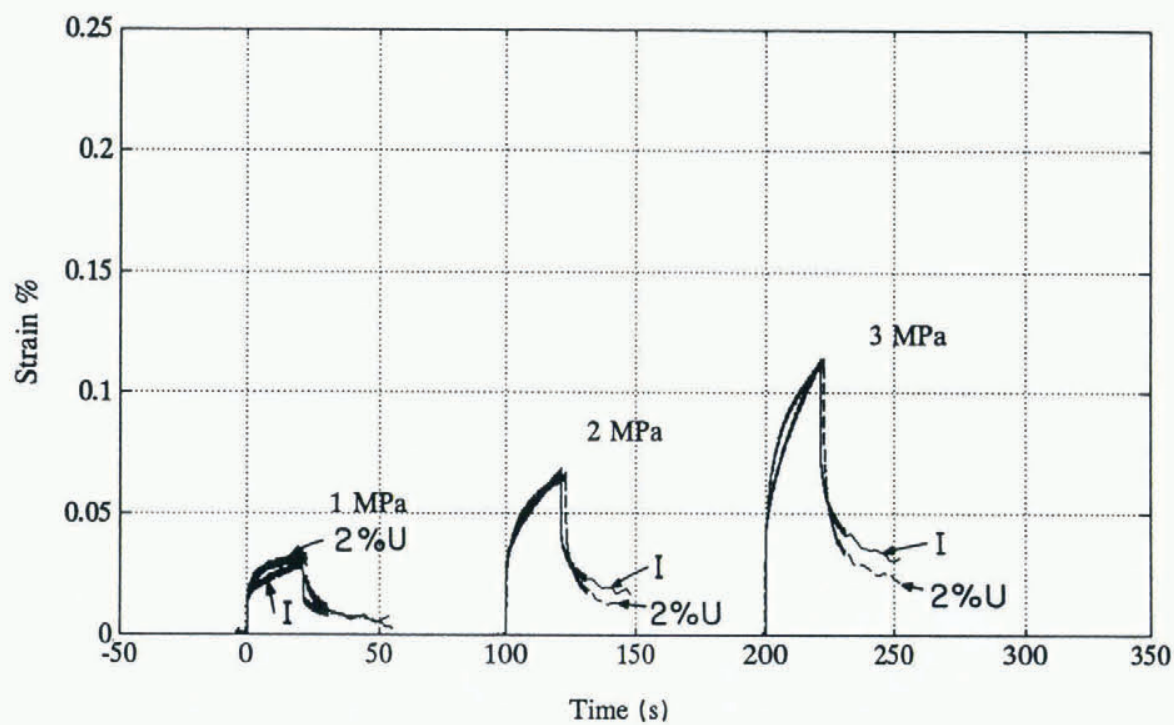

Fig. 12. Creep response of intact (I) and $2 \%$ uniaxially damaged ice $(2 \% \mathrm{U})$, under 5 MPa triaxial confinement for 1,2 and $3 \mathrm{MPa}, 20$ s, pulse loads. 


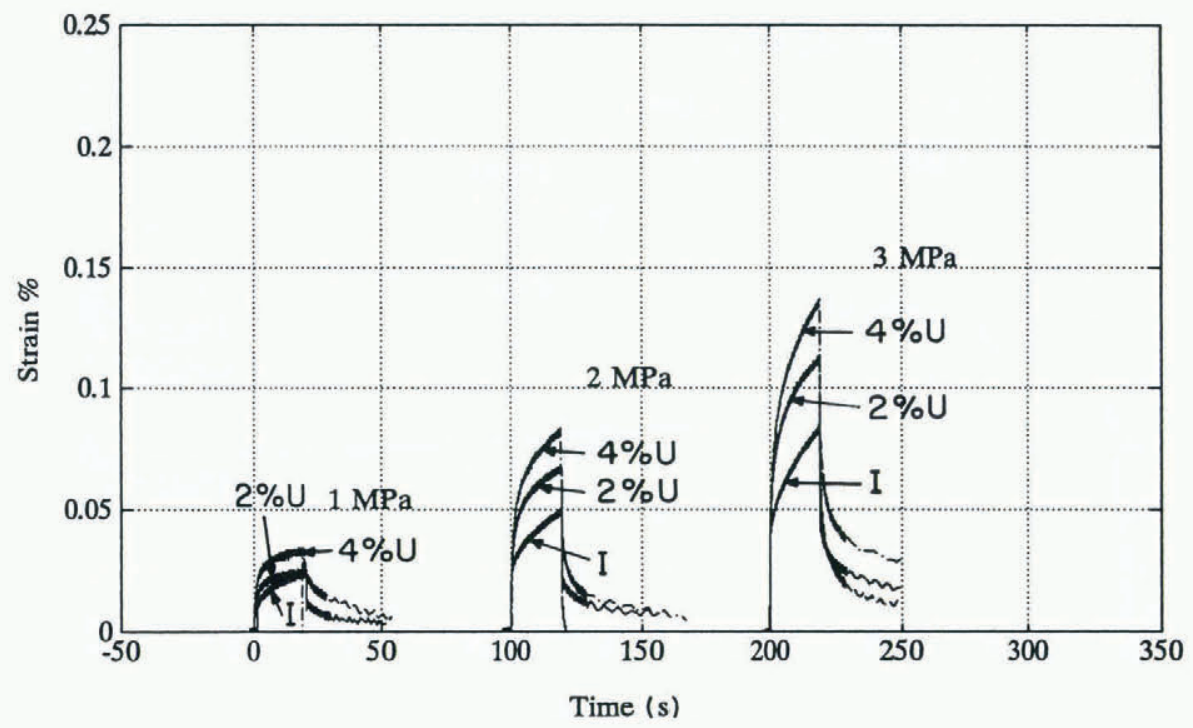

Fig. 13. Creep response of intact (I) and $2 \%$ and $4 \%$ uniaxially damaged ice $(2 \% \mathrm{U}, 4 \% \mathrm{U})$, under $10 \mathrm{MPa}$ triaxial confinement for 1, 2 and $3 \mathrm{MPa}, 20$ s, pulse loads.

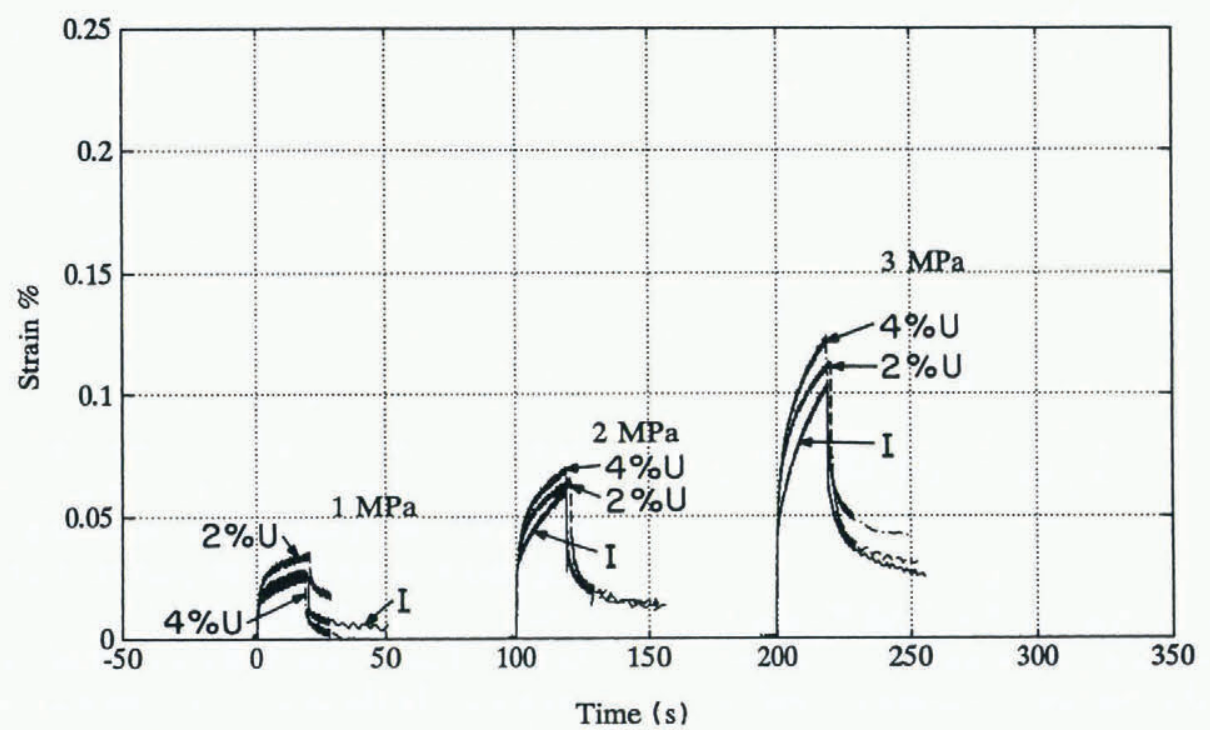

Fig. 14. Creep response of intact (I) and $2 \%$ and $4 \%$ uniaxially damaged ice $(2 \% U, 4 \% U)$, under 20 MPa triaxial confinement for 1, 2 and $3 \mathrm{MPa}, 20$ s, pulse loads.

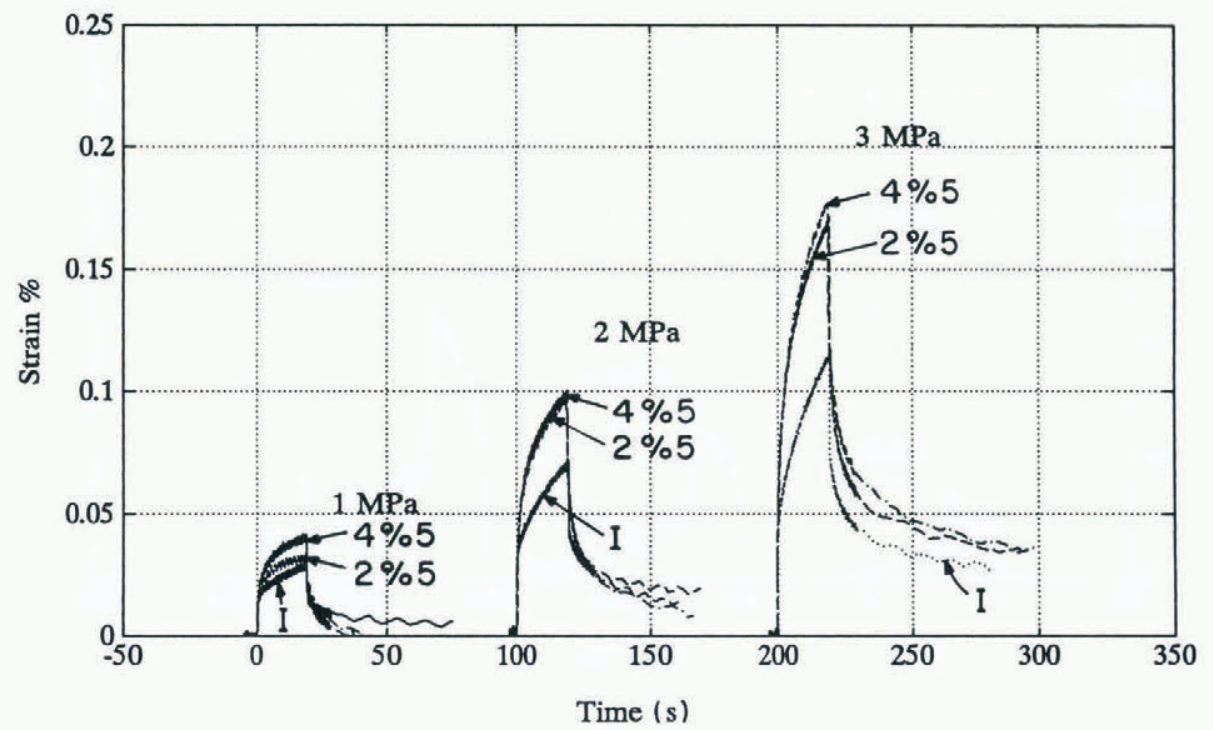

Fig. 15. Creep response of intact (I) and $2 \%$ and $4 \%$ triaxially damaged ice $(2 \% 5,4 \% .5)$, under 5 MPa triaxial confinement for 1, 2 and $3 \mathrm{MPa}, 20$ s, pulse loads. 


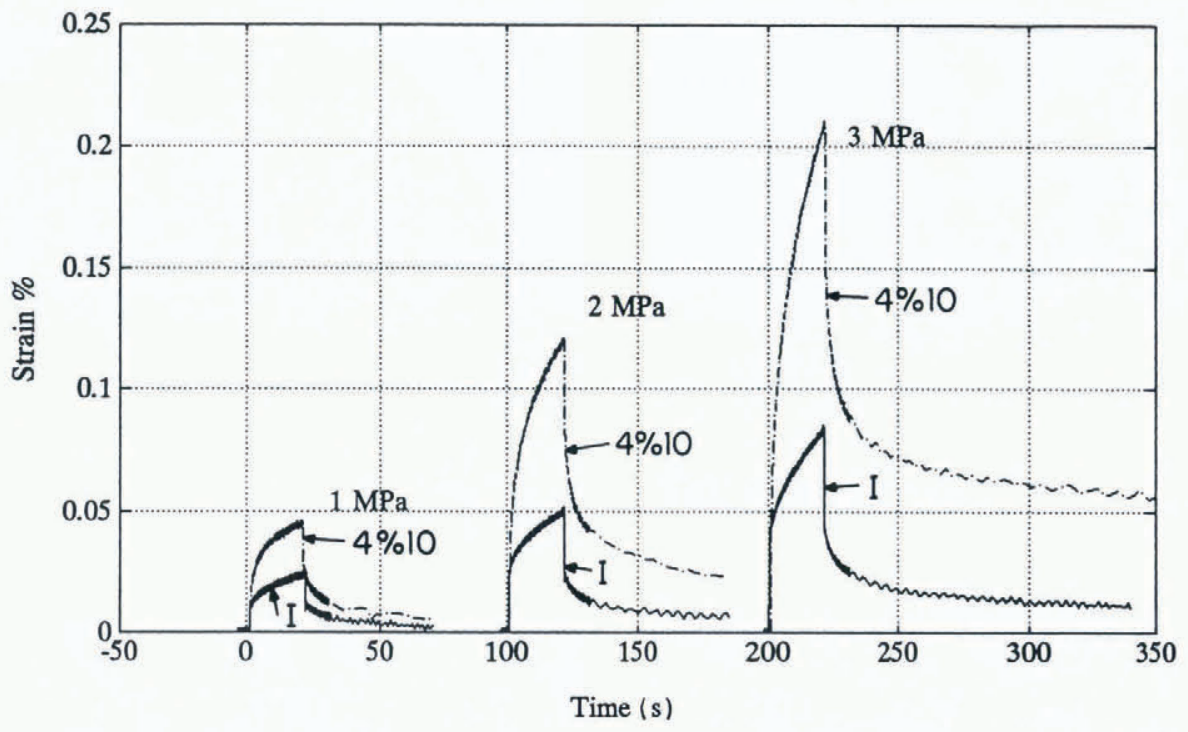

Fig. 16. Creep response of intact (I) and 4\% triaxially damaged ice (4\% 10), under 10 MPa triaxial confinement for 1, 2 and $3 \mathrm{MPa}, 20$ s, pulse loads.
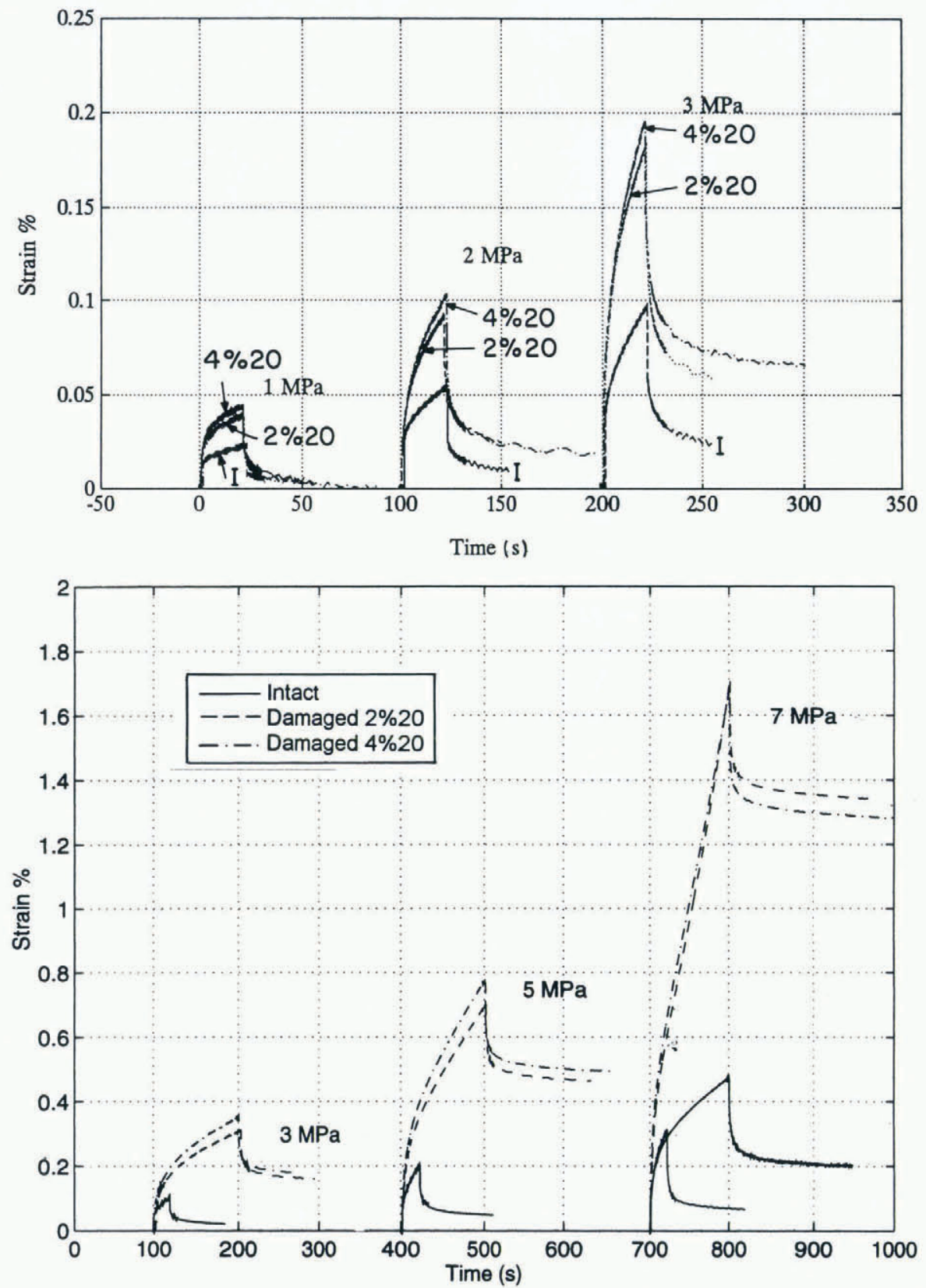

Fig. 17. (a) Creep response of intact (I) and $2 \%$ and $4 \%$ triaxially damaged ice (2\%20, 4\% 20), under 20 MPa triaxial confinement for (a) 1,2 and $3 \mathrm{MPa}, 20$ s, pulse loads, (b) 3,5 and $7 \mathrm{MPa}, 100$ s, pulse loads. 


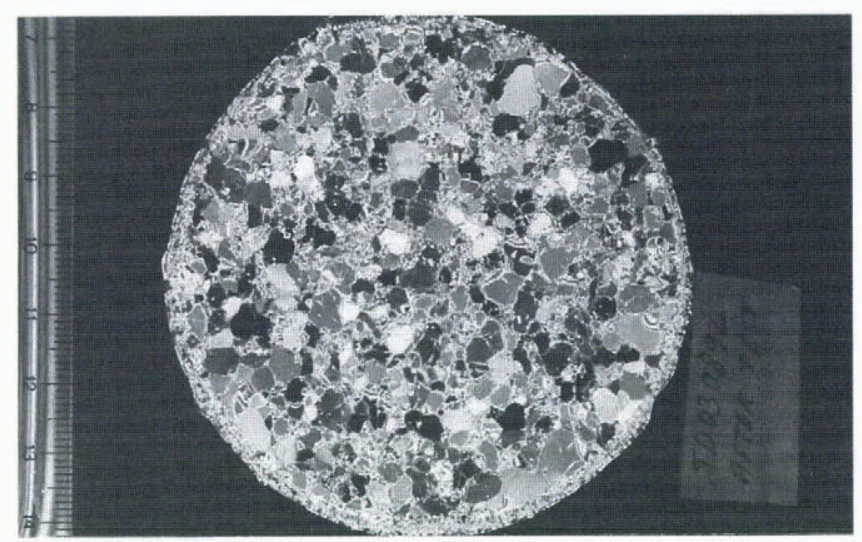

a

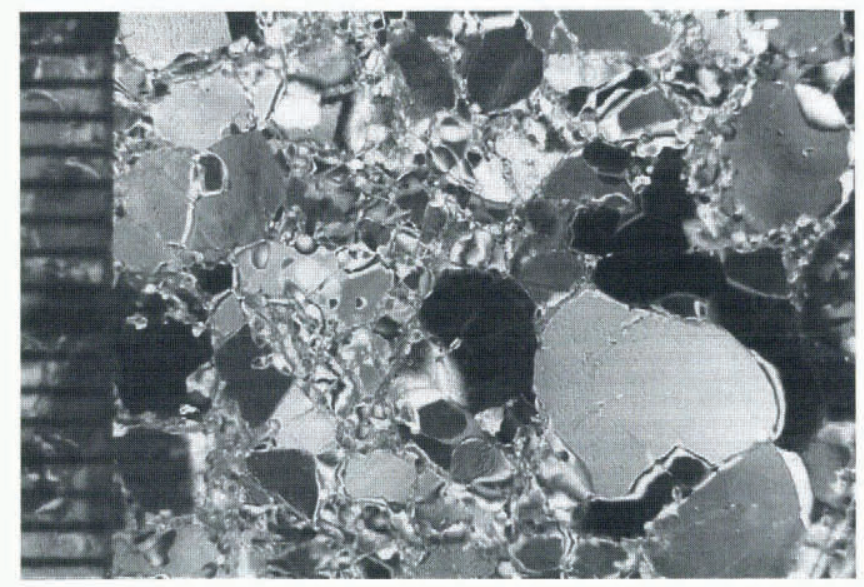

b

Fig. 18. Thin section of a specimen having undergone $2 \%$ uniaxial damage $(2 \% \mathrm{U})$ and a 1, 2, 3,1 MPa, 20 s, pulse-load sequence under triaxial confinement of $10 \mathrm{MPa}$.

thereby introducing anisotropy. Upon the application of confinement, this sample returned much closer to its original volume. This response would result from the closure of cracks. Ice with closed cracks (due to confinement) behaves similarly to intact ice, resulting in reduced elastic and creep strains (Rist and others, 1994). The friction between crack surfaces plays an important role in this case. The effect of friction between closed-crack surfaces may aiso explain why under $5 \mathrm{MPa}$ confinement, the creep strain of damaged ice was almost the same as that of intact ice. When the confinement was increased to 10 or $20 \mathrm{MPa}$, recrystallization and pressure melting between grains or along crack surfaces could occur, and the creep response of uniaxially damaged ice was increased.

The ice went through substantial microstructural change during testing. Figure 21, a thin section of a sample damaged uniaxially to a total strain of $2 \%$ at $10^{-4} \mathrm{~s}^{-1}$, shows the formation of cracks along the axis of loading and the development of a fine-grained structure between a number of grain boundaries, or along cracks.

Figures 18 and 22 show the microstructure of specimens subject to confining pressure and to load pulses after a $2 \% \mathrm{U}$ damage step. A small number of stress-difference pulses, up to $3 \mathrm{MPa}$, were used under $5 \mathrm{MPa}$ (Fig. 22) and $10 \mathrm{MPa}$ (Fig. 18) confinement. The cracks and fine-grained structure produced by the damage step were observed. At $10 \mathrm{MPa}$ (Fig. 18) the higher confinement resulted in a clear increase in the extent and degree of recrystallization to a finer-grained structure.

The structure after damage under a triaxial stress state,

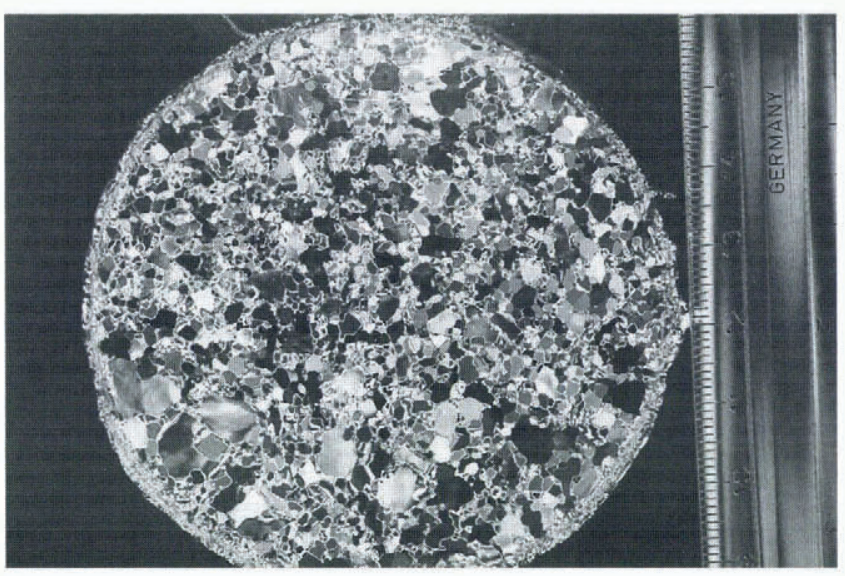

a

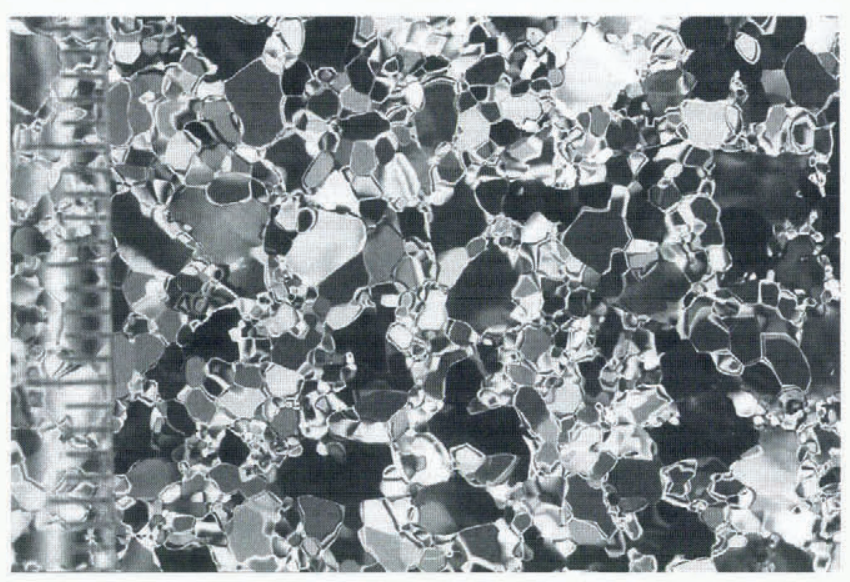

b

Fig. 19. Thin section of a specimen having undergone $4 \%$ strain at a strain rate of $10^{-4} s^{-1}$ under triaxial confinement of $20 \mathrm{MPa}$.
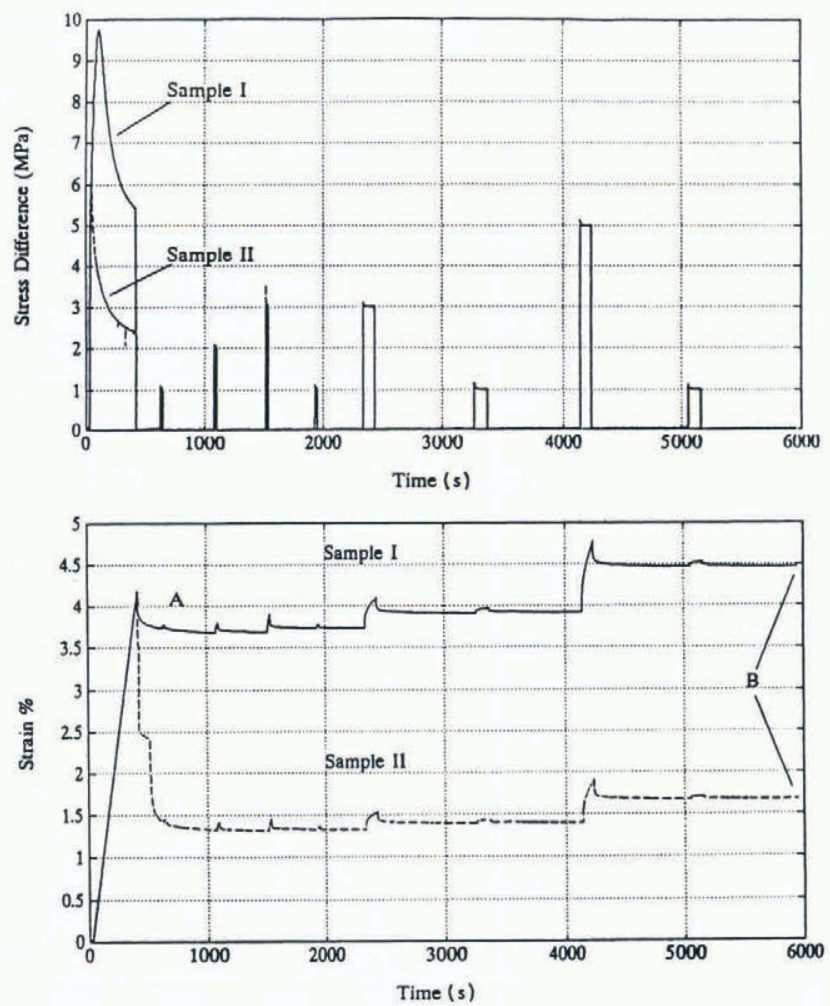

Fig. 20. Comparison of creep response of uniaxially (sample II, $4 \% U$ ) and triaxially ( sample I, 4\% 10) damaged ice under 10 MPa triaxial confinement. 


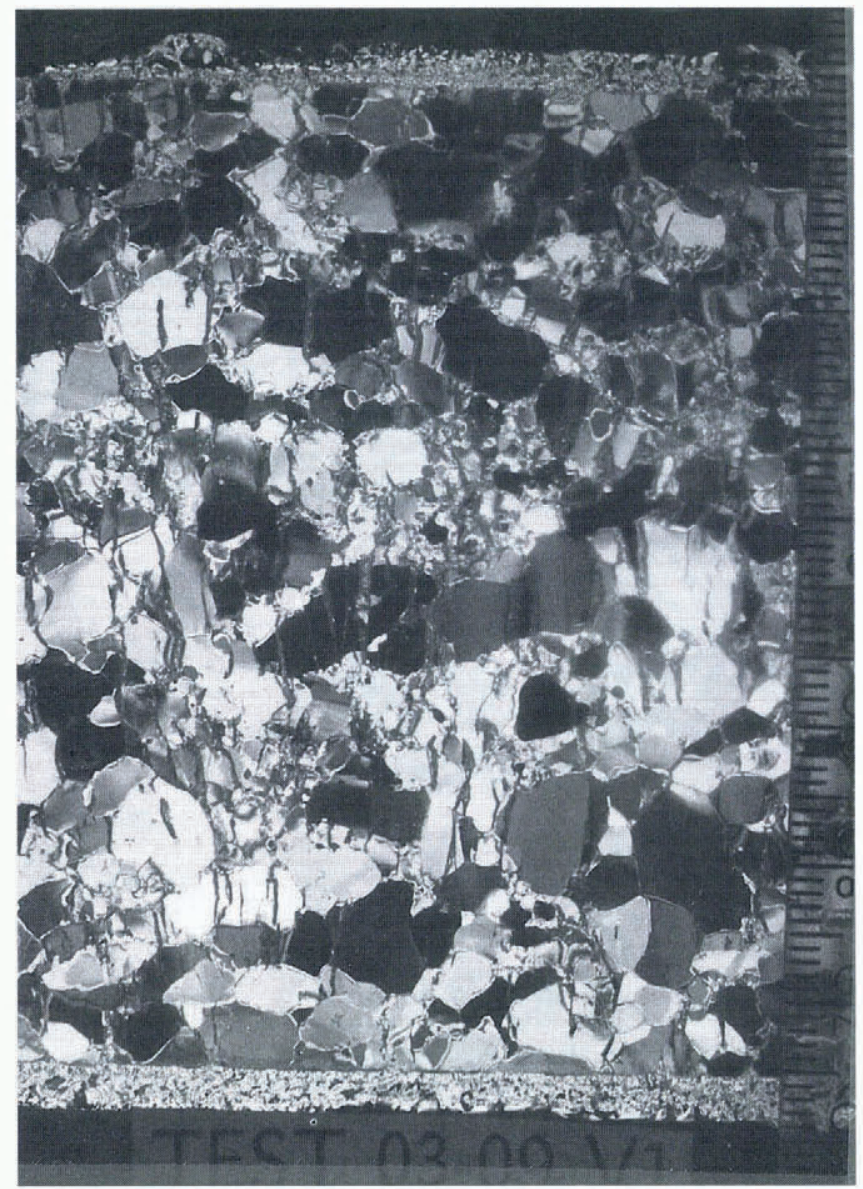

Fig. 21. Thin section through a uniaxially damaged sample (Kenny, 1992).

4\%20, is shown in Figure 19. Cracks are no longer apparent, and the fine-grained structure now extends throughout the sample, with few grains unaffected. An extensive number of stress-difference pulses, up to $7 \mathrm{MPa}$, were applied under the higher $20 \mathrm{MPa}$ confinement. Ice damaged to $4 \% 20$ showed no cracks and an extensive and complete recrystallization to a fine-grained structure (Fig. 23). Attempts were made to identify any changes in the crystal orientations before and after tests. Two samples were examined before and after a total axial strain of $2 \%$. The orientation of approximately 100 grains was examined with no significant preferred orientation evident (personal communication from S. K. Singh, 1996).

\subsection{Pressure reduction tests}

\subsubsection{Rationale and programme}

Extrusion and spalling of crushed ice in actual ice-structure interaction (Frederking and others, 1990) may result in sudden reductions in confining pressures and a corresponding increase in stress difference. In addition to the compression tests to characterize creep enhancement as described above, a preliminary investigation of the effect of sudden confinement-pressure drops on creep rate has been undertaken.

Three tests contrast two confining pressures and two damage levels:

Test A: 2\% 10 damage, $7 \mathrm{MPa}$ load for $100 \mathrm{~s}$, under $10 \mathrm{MPa}$ triaxial confinment reduced to $5 \mathrm{MPa}$ at $20 \mathrm{~s}$.

Test B: 2\% 10 damage, $7.65 \mathrm{MPa}$ load for $100 \mathrm{~s}$, under $20 \mathrm{MPa}$ triaxial confinement reduced to $5 \mathrm{MPa}$ at $20 \mathrm{~s}$.
Test C: 4\%20 damage, $7.65 \mathrm{MPa}$ load for $100 \mathrm{~s}$, under $20 \mathrm{MPa}$ triaxial confinement reduced to $5 \mathrm{MPa}$ at $20 \mathrm{~s}$.

After damaging in each test, a pulse load of $7 \mathrm{MPa}$ for test $\mathrm{A}$, and $7.65 \mathrm{MPa}$ for tests $\mathrm{B}$ and $\mathrm{C}$ was applied for $100 \mathrm{~s}$ under the corresponding confining pressure. After $20 \mathrm{~s}$ of this $100 \mathrm{~s}$ period had elapsed, the triaxial confining pressure was instantaneously dropped from its initial level to $5 \mathrm{MPa}$ for the rest of the pulse load. This pressure drop was executed without a corresponding drop in the applied force as measured by the external load cell, effectively increasing the stress difference to 10.14 MPa for test $\mathrm{A}$ and $16.77 \mathrm{MPa}$ for tests B and C.

\subsubsection{Results and discussion}

Figure 24 shows the strain-time curves for the three tests. During test A the drop in confinement from 10 to $5 \mathrm{MPa}$ resulted in a substantial increase in deformation rate from $0.025 \% \mathrm{~s}^{-1}$ at $0-20 \mathrm{~s}$ to $0.175 \% \mathrm{~s}^{-1}$ at $20-40 \mathrm{~s}$. Therefore, a $7-$ fold increase in deformation rate occurred compared to a 1.45 -fold increase in stress difference. Test $\mathrm{B}$ with the same damage but a pressure drop from 20 to $5 \mathrm{MPa}$ showed a deformation rate of $1.49 \% \mathrm{~s}^{-1}$ after $20 \mathrm{~s}$. This reflects a 60 -fold increase in deformation rate for a 2.19-fold increase in stress difference. The greater damage of test $\mathrm{C}$ results in a marginal increase in creep during the $0-20 \mathrm{~s}$ period compared to tests $\mathrm{A}$ and $\mathrm{B}$. It has little effect on the deformation rate after the release of pressure relative to test $\mathrm{B}$, conducted at a lower level of damage.

\section{DISGUSSION}

A range of tests has been conducted to determine fundamental behaviour of ice under a range of stress states and stress history. The test programme was aimed at understanding the response of ice within high-pressure zones that occur during ice-structure interaction (e.g. critical zones in Jordaan and others, 1991). As part of the work on critical zones, analyses of stresses and strains using finiteelement methods have been carried out (Xiao and others, 1991). These analyses require appropriate constitutive models, based on state variables, as mentioned earlier. The key innovation has been to cause certain damage states by imposing a defined stress history, and then to investigate the response of the damaged ice. The present paper gives an overview of the test programme aimed at improved modelling of the processes involved. Other tests include, first, a brief investigation on intact ice with confining pressures and a small stress difference aimed at obtaining the intrinsic response to stress, and secondly, tests on damaged ice in which changes in hydrostatic pressure occur, simulating the fluctuation of loads in the field ("pressure drop" tests).

The tests on intact ice with confining pressures and low shear stresses aimed at defining the intrinsic creep response in the absence of microcracking showed that an accelerated creep rate occurred at relatively low shear stresses. Hence, a minimum creep rate occurred under these conditions. Although microcracking was suppressed, recrystallization and, in one case, void formation occurred. The intrinsic behaviour in the absence of any microstructural changes is rather elusive!

Ice damaged uniaxially and triaxially showed enhancement of creep under triaxial loading conditions. This was 

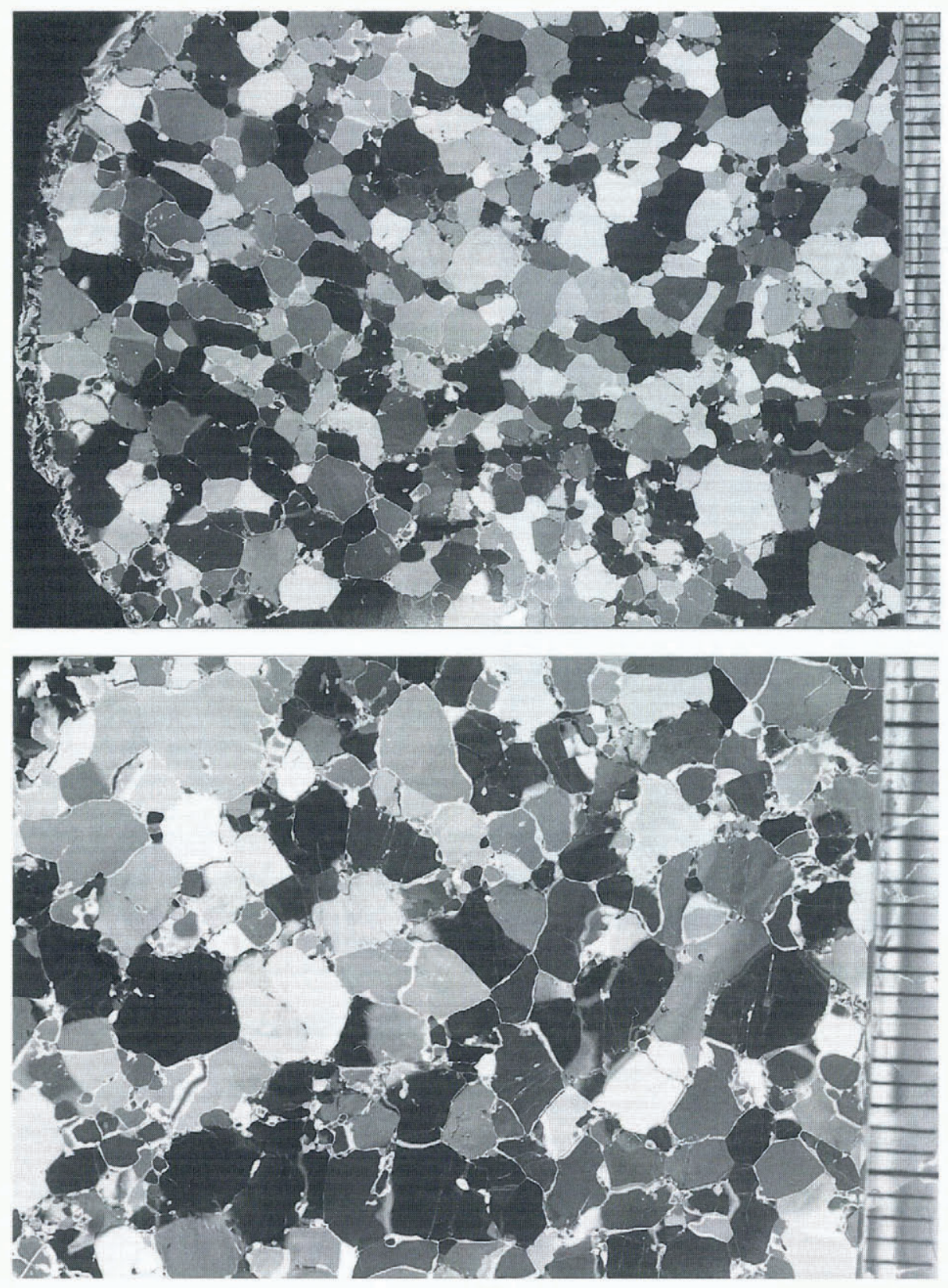

Fig. 22. Thin section of a specimen having undergone $2 \%$ uniaxial damage $(2 \% U)$ and a 1, 2, 3, $1 \mathrm{MPa}, 20 \mathrm{~s}$, pulse-load sequence under triaxial confinement of $5 \mathrm{MPa}$.

much more pronounced in the case of damage created under triaxial conditions. For example, in Figure 14, the response of the specimen damaged to $4 \%$ uniaxially $(4 \% \mathrm{U})$ is not very different from the response of the intact ice (I) specimen, whereas in Figure 17, the specimen damaged to $4 \%$ triaxially $(4 \% 20)$ is significantly softer than the intact ice (I) specimen. The $4 \% 20$ sample is only slightly softer than the $2 \% 20$ sample.

The type of damage was also different, resulting in the difference in response noted. Uniaxially damaged specimens contained microcracks parallel to the stressed direction which tend to close under triaxial confinement. Damage under triaxial conditions was largely associated with recrystallization, and some cracking at the lower confining pressures. The samples damaged uniaxially therefore would be highly cracked by the damage. When retested under confined conditions, the confinement would close the cracks, resulting in a sample close to the original intact ice. Hence, a strain-time curve not very different from that of an undamaged sample resulted. Samples damaged under confining pressure exhibit reduced microcracking at a strain of $2 \%$ or $4 \%$. Considerable dislocation multiplication would occur and the ice would be in the tertiary creep range where recrystallization is known to occur (Glen and Ives, 1988). Both these effects would lead to softer ice, which is what was observed when the samples were reloaded under the pulse loads. The remaining question is why a $2 \% 20$ and a $4 \% 20$ sample showed little difference on reloading. It is known that in single crystals of ice the initial dislocation content has a large effect on the peak stress, but has little effect on the flow stress at strains beyond the peak value (Jones and Glen, 1969). Thus, for the present polycrystals, damaged beyond the peak stress to either $2 \%$ or $4 \%$ strain (usually the peak stress occurs at $1 \%$ or less), the flow stress would be similar, and hence, when reloaded, they would behave similarly, as was indeed found. From another perspective, the value of state variable $S$ from Equation (1) would be very similar in the case of the two damage states. 


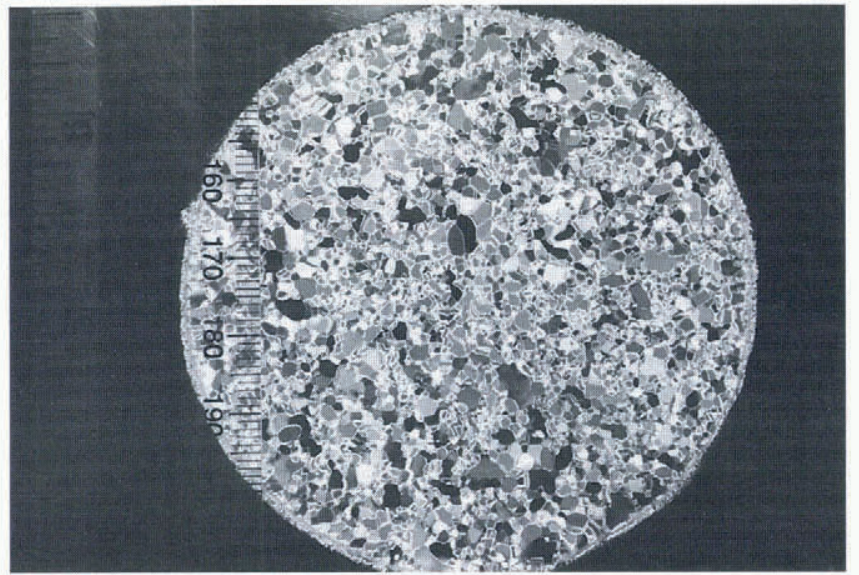

a

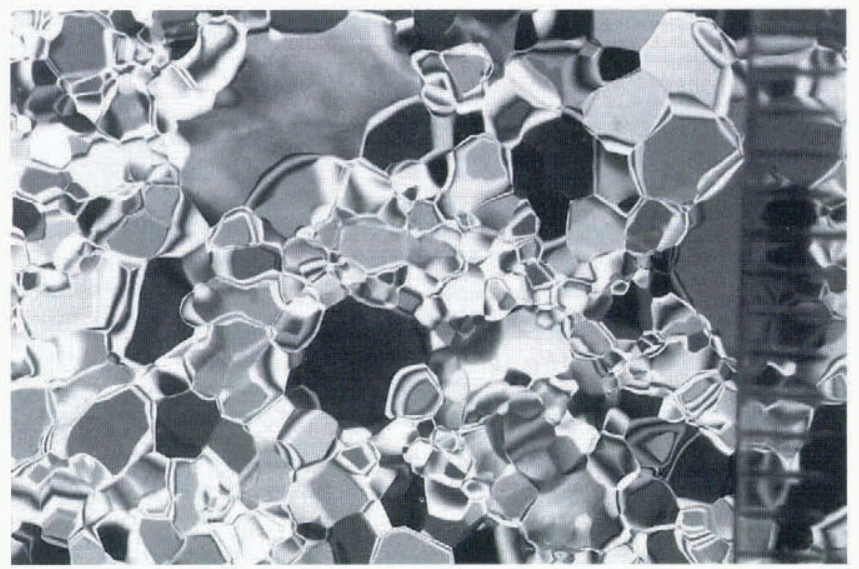

b

Fig. 23. Thin section of a specimen having undergone $4 \%$ damage at $20 \mathrm{MPa}$ confinement $(4 \% 20)$ and a 1, 2, 3, $1 \mathrm{MPa}, 20 \mathrm{~s}$, and a 3, 1, 5, 1, 7, $1 \mathrm{MPa}, 100 \mathrm{~s}$, pulse-load sequence under triaxial confinement of $20 \mathrm{MPa}$.

The ensuing strains would be expected to be similar.

Of particular importance were the very high creep rates in triaxially damaged ice at high deviatoric stresses (Fig. $17 b)$. Very high strain rates were also observed in the pressure-drop tests (Fig. 24). The creep is highly non-linear with stress. The high rates could be associated with the formation of critical zones. Figure 25 shows the strain rate in various tests. It is clear that stress history has a very significant effect on strain rate. This will be particularly evident in those tests, such as the pressure-drop tests, where the ice was significantly damaged and yet sustains very high shear stresses. A specimen under $22 \mathrm{MPa}$ stress difference under these conditions creeps at a rate approximately $10^{6}$ times the rate for intact ice at $1 \mathrm{MPa}$ proposed by Sinha (1981). As mentioned earlier, the elastic strain is not strongly influenced by the damage state, whereas the delayed elastic and secondary creep strain are significantly enhanced. Triaxially damaged ice showed insignificant change in elastic strain.

The importance of shearing can be seen by contrasting two tests. In the first, under high confinement, typically 10 $20 \mathrm{MPa}$, the ice undergoes a complete recrystallization (breakdown of structure) when subjected to a stress deviator at a rate of $10^{-4} \mathrm{~s}^{-1}$ reaching a maximum stress of about $10 \mathrm{MPa}$. On the other hand, hydrostatic pressure (40 MPa) applied for $1.5 \mathrm{~h}$ resulted in no observable change in crystal

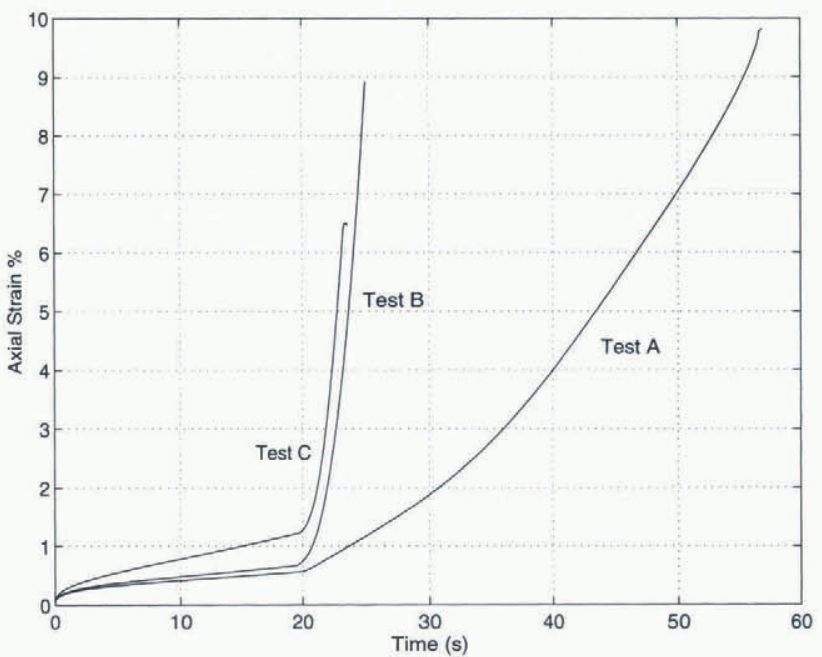

Fig. 24. Effect of sudden confinement-pressure drops on the axial strain rate: test $A, 2 \% 10$ damage, $7 \mathrm{MPa}$ load for $100 \mathrm{~s}$, under $10 \mathrm{MPa}$ triaxial confinement reduced to $5 \mathrm{MPa}$ at 20 s; test B, 2\% 10 damage, 7.65 MPa load for 100 s, under $20 \mathrm{MPa}$ triaxial confinement reduced to $5 \mathrm{MPa}$ at $20 \mathrm{~s}$; and test $C, 4 \% 20$ damage, $7.65 \mathrm{MPa}$ load for $100 \mathrm{~s}$, under $20 \mathrm{MPa}$ triaxial confinement reduced to $5 \mathrm{MPa}$ at $20 \mathrm{~s}$.

size. The tests show clearly that shear stress results in recrystallization, and that hydrostatic pressure alone has little effect on crystal size. At the same time, hydrostatic pressure can permit the application of the high shear necessary to cause extensive recrystallization. Tests in the field (Frederking and others, 1990) show that these states of stress and associated changes to the microstructure occur during ice-structure interactions.

As noted, the present tests show that a reduction in grain-size occurs under the action of shear stress. Under uniaxial stress, the recrystallization occurs near zones where microfracturing takes place. This was also observed in large-grained $(5 \mathrm{~mm})$ specimens by Cole (1987). In the presence of confining pressure, the recrystallization is spread uniformly across the specimen, including cases where there is no evidence after the test of microfracturing. The process is deformation-induced and therefore, by definition, dynamic (Poirier, 1985). The relative roles of sub-

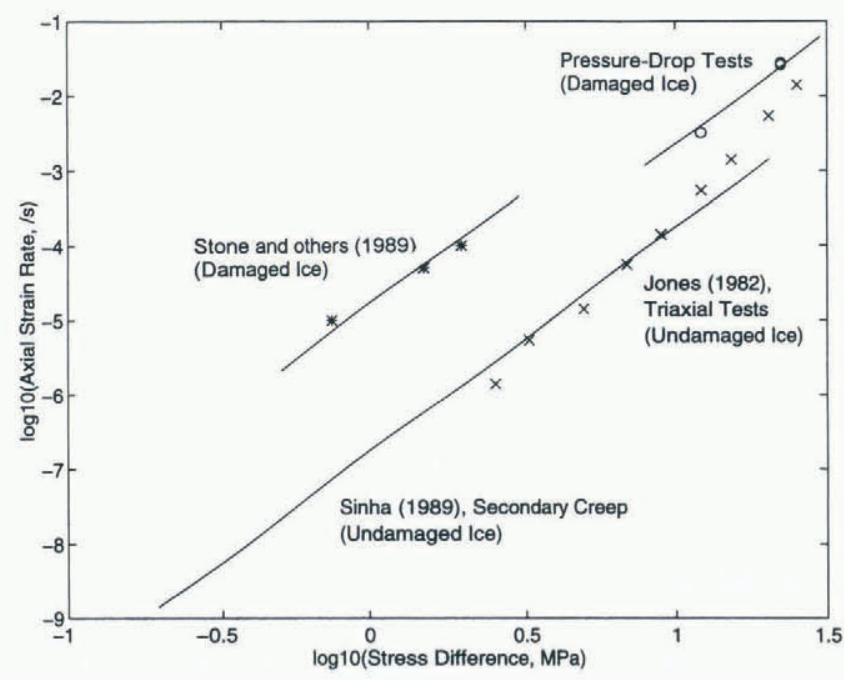

Fig. 25. Strain rate of pressure-drop tests relative to previous work. 
grain development by dislocation walls and by microfracturing are not clear. The recrystallization mechanisms do not appear to correspond to grain-boundary migration and enlargement of grains associated with the difference in strain energy between grains. This mechanism was suggested by Duval and others (1983), who associated dynamic recrystallization with a critical strain-energy difference. Rather, an overall reduction in grain-size and release in strain energy of the grains with an increase in shear deformation rate is found. In the review paper by Urai and others (1986), the mechanism of diffusive mass transfer associated with decrease in grain-size by recrystallization is discussed. This can lead to a softening of the material. The relationships show strain rates that are linear with stress. In the present case, extreme non-linearity has been found. In a recent publication, Jacka and Li (1994) have suggested that an equilibrium crystal size is a "balance" between crystal growth with time as a function of temperature and crystal size as a result of deformation. The temperature dependence of these two effects is similar, and consideration of the activation energies for the two processes indicates that it may be appropriate to cancel these effects. Under these conditions, very small grain-sizes for the high stresses used in the present experiments are indicated. Our strain rates are much higher than those considered by Jacka and Li (1994). The formation of small grains at high stresses is well known in other materials (Derby, 1990) and may result from a high nucleation rate of new crystals for a given recrystallized volume. The enhanced creep rate in the damaged specimens is associated with the recrystallization process. Increased grain-boundary volume and associated sliding, or favourable orientation (for creep) of the $c$-axis direction after recrystallization could also contribute to higher creep rates.

Duval and others (1983) quote a value of $1000 \mathrm{Jm}^{-3}$ as critical strain-energy density for grain-boundary migration. In their tests, which were uniaxial at low stress levels $(1-2 \mathrm{MPa})$, this was shown to exist only at local stress concentrations. In our tests, the strain-energy density associated with the stress difference could be as high as $5000 \mathrm{Jm}^{-3}$, excluding terms associated with volume change. The latter could amount to almost $40000 \mathrm{Jm}^{-3}$. This would become available in situations where the volumetric stress is relieved, as occurs in the pressure-reduction tests reported here. This also happens repeatedly in field situations where confining pressures are released.

\section{ACKNOWLEDGEMENTS}

Financial support for this research was provided through the Canada-Newfoundland Offshore Development Fund, Natural Sciences and Engineering Research Council of Canada, Mobil Oil Canada Properties, National Energy Board and Memorial University of Newfoundland. The authors wish to thank Dr R. A. Schapery of the University of Texas at Austin for his helpful suggestions.

\section{REFERENCES}

Barnes, P., D. Tabor and J. C. F. Walker. 1971. The friction and creep of polycrystalline ice. Proc. R. Soc. London, Ser. A, 324(1557), 127-155.

Cole, D. M. 1986. Effect of grain size on the internal fracturing of polycrystalline ice. CRREL Rep. 86-5.
Cole, D. M. 1987. Strain-rate and grain-size effects in ice. J. Glaciol., 33(115), $274-280$.

Derby, B. 1990. Dynamic recrystallization and grain size. In Barber, D. J and P. G. Meredith, eds. Deformation processes in minerals, ceramics and rocks. London, Unwin Hyman, 354-364.

Duval, P., M. F. Ashby and I. Anderman. 1983. Rate-controlling processes in the creep of polycrystalline ice. J. Phys. Chem., 87 (21), 4066-4074.

Frederking, R. and L.W. Gold. 1975. Experimental study of edge loading of ice plates. Can. Geotech. 7., 12 (4), 456-463.

Frederking, R., I. J. Jordaan and J. S. McCallum. 1990. Field tests of ice indentation at medium scale, Hobson's Choice Ice Island, 1989. IAHR. Symposium on Ice, Espoo, Finland, August 20-24, 1990. Proceedings. Vol. 2. Espoo, Helsinki University of Technology, 931-944.

Glen, J.W. and D. J. Ives. 1988. Fish antifreeze proteins and the creep of polycrystalline ice. f. Glaciol., 34(118), 291-292.

Hobbs, P. V. 1974. Ice physics. Oxford, Clarendon Press.

Jacka, T. H. 1984. The time and strain required for development of minimum strain rates in ice, Cold Reg. Sci. Technol., 8(3), 261-268.

Jacka, T. H. and L. Jun. 1994. The steady-state crystal size of deforming ice. Ann. Glaciol., 20, 13-18.

Jones, S. J. 1982. The confined compressive strength of polycrystalline ice. $\mathcal{J}$. Glaciol., 28 (98), 171-177.

Jones, S. J. and J. W. Glen. 1969. The mechanical properties of single crystals of pure ice. .j. Glaciol., 8 (54), 463-473.

Jordaan, I. J. and G.W. Timco. 1988. Dynamics of the ice-crushing process. f. Glaciol., 34(118), 318-326.

Jordaan, I. J. and J. Xiao. 1993. Interplay between damage and fracture in ice structure interaction. IAHR 92. 11th International Symposium on Ice, Banff, Alberta, Canada, June 15-19, 1992. Proceedings. Vol. 3. Edmonton, Alta, University of Alberta. Department of Civil Engineering, 14481467.

Jordaan, I. J., K. P. Kennedy, R. F. McKenna and M. A. Maes. 1991. Loads and vibration induced by compressive failure of ice. In Sodhi, D.S., ed. Cold Regions Engineering. Proceedings of the 6th International Specialty Conference, February 26-28, 1991, West Lebanon, NH. New York, American Society of Civil Engineers, 638 - 649 .

Jordaan, I. J., B. M. Stone, R. F. McKenna and M. K. Fuglem. 1992. Effect of microcracking on the deformation of ice. Can. Geotech. J., 29 (1), 143-150.

Kennedy, K. P., I. J. Jordaan, M. A. Maes and A. Prodanovic. 1994. Dynamic activity in medium-scale ice indentation tests. Cold Reg. Sci. Technol., $22(3), 253-267$.

Kenny, S. P. 1992. The influence of damage on the creep behaviour of ice subject to multiaxial compressive stress states. (M.Eng. thesis, Memorial University of Newfoundland. Faculty of Engineering and Applied Science.)

Kheisin, D. E. and N.V. Cherepanov. 1973. Change of ice structure in the zone of impact of a solid body against the ice cover surface. Problems of the Arctic and Antarctic 33-35, 239-245.

Offenbacher, E. L., I. C. Roselman and D. Tabor. 1973. Friction, deformation, and recrystallization of single crystals of ice Ih under stress. In Whalley, E., S. J. Jones and L. Gold, eds. Physics and Chemistry of Ice: papers presented at the Symposium on the Physics and Chemistry of Ice, held in Ottawa, Canada, $14-18$ August 1972. Ottawa, Ont., Royal Society of Canada, 377-381.

Poirier, J. -P. 1985. Creep of crystals. Cambridge, Cambridge University Press.

Rist, M. A., S. J. Jones and T. D. Slade. 1994. Microcracking and shear fracture in ice. Ann. Glaciol., 19, 131-137.

Schapery, R. A. 1981. On viscoelastic deformation and failure behaviour of composite materials with distributed flaws. Adv. Aerospace Struct. Mater., AD-01, 5-20.

Schapery, R. A. 1991. Models for the deformation behavior of viscoelastic media with distributed damage and their applicability to ice. In Jones, S. J., R. F. McKenna, J. Tillotson and I. J. Jordaan, eds. Ice-structure Interaction. IUTAM-IAHR Symposium, St. Fohn', Newfoundland, Canada. Berlin, etc., Springer-Verlag, 191-230.

Singh, S. K. 1993. Mechanical behaviour of viscoelastic material with changing microstructure. (Ph.D. thesis, Memorial University of Newfoundland. Faculty of Engineering and Applied Science.)

Sinha, N. K. 1981. Constant stress rate deformation modulus of ice. POAC81. The Sixth International Conference on Port and Ocean Engineering under Arctic Conditions, Québec, Canada, July 27-31, 1981. Proceedings. Vol. 1. Québec, Qué., Université Laval, 216-224.

Sinha, N. K. 1989. Microcrack-enhanced creep in polycrystalline material at elevated temperature. Acta Metall., 37(11), 3107-3118.

Sinha, N. K. 1990. Is minimum creep rate a fundamental material property? In Ayorinde, O. A., N. K. Sinha and D. S. Sodhi, eds. Proceedings of the Ninth International Conference on Offshore Mechanics and Arctic Engineering1990. Vol. IV. Arctic/Polar Technology. New York, American Society of Mechanical Engineers, 283-288.

Stone, B. M., I. J. Jordaan, S. J. Jones and R. F. McKenna. 1989. Damage of 
isotropic polycrystalline ice under moderate confining pressures. In Axelsson, K.B.E. and L. A. Fransson, eds. POAC 89. The 10th International Conference on Port and Ocean Engineering under Arctic Conditions, June 12-16 1989, Luleä, Sweden. Proceedings. Vol. I. Luleå, Tekniska Högskolan i Luleå, 408-419.

Urai, J. L., W. D. Means and G. S. Lister. 1986. Dynamic recrystallization of minerals. In Hobbs, B. E. and H. C. Heard, eds. Mineral and rock deformation: laboratory studies - the Paterson Volume. Washington, DC, American Geophysical Union, 161-199. (Geophysical Monograph 36.)
Xiao, J. and I. J. Jordaan. 1996. Application of damage mechanics to ice failure in compression. Cold Reg. Sci. Technol., 24 (3),305-322.

Xiao, J., I. J. Jordaan, R. F. McKenna and R. M. W. Frederking. 1991. Finite element modelling of spherical indentation tests on ice. In Muggeridge, D. B., D. B. Colbourne and H. M. Muggeridge, eds. POAC'91. The Ilth International Conference on Port and Ocean Engineering under Arctic Conditions, September 24 28, 1991, St. John's, Canada. Proceedings. Vol. I. St. John's, Nfld, Memorial University of Newfoundland. Ocean Engineering Research Centre, 471-485.

MS received 10 May 1995 and accepted in revised form 9 July 1996 